\title{
Fungibility and the Choice of Aid
} Modalities

\author{
The Red Herring Revisited
}

Stefan Leiderer*

August 2012

\begin{abstract}
The 'right' choice of instruments and modalities to provide aid to developing countries in support of poverty reduction and economic development is arguably the most contested issue in the current international debate on aid effectiveness. A particular controversy exists around the provision of aid in the form of budget support to avoid high transaction costs and other shortcomings of traditional project-based aid. Critics argue that this kind of 'programme aid' involves unacceptably high fiduciary risks due to the fungibility of budgetary funds. A more recently proposed form of aid is in the form of results-based aid or aid on delivery. Proponents argue that this provides donors with better control over the use of aid resources.
\end{abstract}

Keywords: aid, fungibility, government spending

JEL classification: F35, H50, O23

\section{Copyright (C) UNU-WIDER 2012}

* German Development Institute, Bonn, Germany, email: Stefan.Leiderer@die-gdi.de

This study has been prepared within the UNU-WIDER project 'Foreign Aid: Research and Communication (ReCom)', directed by Tony Addison and Finn Tarp.

UNU-WIDER gratefully acknowledges specific programme contributions from the governments of Denmark (Ministry of Foreign Affairs, Danida) and Sweden (Swedish International Development Cooperation Agency - Sida) for the Research and Communication (ReCom) programme. UNU-WIDER also acknowledges core financial support to UNU-WIDER's work programme from the governments of Finland (Ministry for Foreign Affairs), the United Kingdom (Department for International Development), and the governments of Denmark and Sweden. 
This paper demonstrates in a simple principal-agent framework with asymmetric information that in the absence of transaction costs, for a wide range of combinations of aid dependency and recipient government commitment to reduce poverty, all three forms of aid are equivalent with regard to fungibility and fiduciary risks. The paper proceeds to demonstrate that as long as donors can rely on the recipient government to be at least minimally committed to poverty reduction, a well co-ordinated modality mix of general budget support and aid on delivery does not bear higher fiduciary risks than project aid. It concludes that if project aid does indeed involve higher transaction costs than budget support, donors should provide aid in the form of such a modality mix, albeit only if they are able (and willing) to closely co-ordinate their support.

\section{Acknowledgements}

I thank Tony Addison, Stephan Klingebiel, Davina Makhan, Peter Hans Matthews, Oliver Morrissey, Eva Terberger, and Miguel Niño-Zarazúa, for their valuable comments. The usual caveats apply.

The World Institute for Development Economics Research (WIDER) was established by the United Nations University (UNU) as its first research and training centre and started work in Helsinki, Finland in 1985. The Institute undertakes applied research and policy analysis on structural changes affecting the developing and transitional economies, provides a forum for the advocacy of policies leading to robust, equitable and environmentally sustainable growth, and promotes capacity strengthening and training in the field of economic and social policy making. Work is carried out by staff researchers and visiting scholars in Helsinki and through networks of collaborating scholars and institutions around the world.

www.wider.unu.edu publications@wider.unu.edu

UNU World Institute for Development Economics Research (UNU-WIDER)

Katajanokanlaituri 6 B, 00160 Helsinki, Finland

Typescript prepared by Author.

The views expressed in this publication are those of the author(s). Publication does not imply endorsement by the Institute or the United Nations University, nor by the programme/project sponsors, of any of the views expressed. 


\section{Introduction: the debate on aid effectiveness and aid modalities}

Over the past decade or so, a broad consensus has emerged among development researchers and aid practitioners that in order to reach ambitious development objectives such as the Millennium Development Goals (MDGs), the effectiveness of international aid to developing countries will have to improve substantially.

This thinking is in part inspired by the somewhat disappointing findings of a relatively large body of quantitative research on macro-economic effects of aid over the past decades (e.g. Rajan and Subramanian 2005, Roodman 2007, Doucouliagos and Paldam 2008).

Although more recent work seems to point to an overall positive record of aid over the past decades (cf. Arndt et al. 2010, Tarp and Mekasha 2011), there is a general understanding (on the donor as well as the recipient side) that the effectiveness of international development cooperation has in the past been compromised by unintended side-effects that have to do with the way aid has traditionally been provided. ${ }^{1}$

Consequently, over the past years much of the political debate on how to make aid more effective has concentrated on principles and modalities for the provision of international aid that could lead to improved effectiveness. A series of High Level Forum (HLF) meetings of ministers, heads of aid agencies and other senior officials in Rome (2003), Paris (2005), Accra (2008) and most recently in Busan (2011) has produced outcome documents that - taken together - delineate the international political agenda for more effective aid (cf. HLF 2003, 2005, 2008, 2011).

At the centre of this aid effectiveness agenda stand the five principles formulated in the Paris Declaration on Aid Effectiveness (HLF 2005): Ownership, Alignment, Harmonization, Managing for Results, Mutual Accountability.

These principles, if applied to development cooperation, are expected to fundamentally enhance the effectiveness of international aid. The proposed way to implement them in practice is through so-called Programme-based Approaches (PBAs), defined by the OECD-DAC, as 'a way of engaging in development co-operation based on the principles of coordinated support for a locally owned programme of development, such as a national development strategy, a sector programme, a thematic programme or a programme of a specific organization' (OECDDAC 2008, 148).

1 One explanation offered for the still unsatisfying results of quantitative studies on aid effectiveness and the observed micro-macro-paradox (i.e. mostly positive evaluations at project and programme level but no significant measurable effects at a macro-level) is that at a macro-level positive effects of aid are (over-) compensated by unintended side-effects and externalities of aid resources. These unintended effects include Dutch disease effects, weakening of policy formulation and planning processes due to the high volatility of aid flows, and, in particular, negative effects on the political and institutional framework in recipient countries. The latter, it is argued, are generated because aid provides resources for recipient governments to serve special interests and rent-seeking activities that undermine democratic and meritocratic structures favorable to economic growth and poverty reduction. Although recent research suggests that no such paradox exists and that aid has indeed been effective over the past decades (Arndt et al. 2010), there seems to exist a general consensus that aid could be made more effective by avoiding some of these unintended side-effects. 
More specifically, according to this official definition, PBAs are characterized by the following features: (i) leadership by the host country or organization; (ii) a single comprehensive programme and budget framework; (iii) a formalized process for donor co-ordination and harmonization of donor procedures for reporting, budgeting, financial management and procurement; (iv) efforts to increase the use of local systems for programme design and implementation, financial management, monitoring and evaluation (ibid).

The PBA concept is essentially a reaction to the poor track record of traditional projectbased aid that is perceived to put enormous strain on both donors' and recipients' financial and administrative capacities. ${ }^{2}$ In summary of the arguments against this traditional form of development cooperation, isolated aid projects are perceived to:

- involve high transaction costs,

- be predominantly supply-driven (following donor rather than recipient priorities) and to generate little ownership for development processes on the recipient side,

- undermine recipients' own administrative and political capacities by establishing parallel systems for managing aid resources, and

- produce only temporally and locally confined effects with little impact on structural and systemic challenges in developing countries.

It is commonly understood that PBAs can be implemented through different aid modalities. In practice, these modalities range from pooled (or basket) funding of specific activities or reform programmes to joint support of sector-wide approaches (SWAps) and sector and general budget support.

Especially general budget support (GBS), although not explicitly referred to in the Paris Declaration on Aid Effectiveness (HLF 2005), is taken by many to be the most consequential instrument to implement the principles of the new aid effectiveness agenda in practice. It involves the support of national development and poverty reduction strategies in developing countries by means of direct financial support to recipient governments' national treasuries (OECD-DAC 2006: 26), instead of funding hundreds or thousands of isolated projects of uncertain relevance to the countries' specific development needs. ${ }^{3}$

2 To illustrate: In 2003, donors financed a total of around 50,000 development cooperation projects and programmes (OECD-DAC 2003:47). According to conservative estimates, in a typical African country at the turn of the millennium, there were around 600 ongoing development cooperation projects (in the case of Burkina Faso alone, for example, there were 1500 projects in 2004), for which each year around 2400 quarterly reports had to be prepared. In addition, this involved about 1000 annual donor missions, usually demanding talks with high-ranking representatives of the partner country (Club du Sahel 2000: 7, Klingebiel et al. 2005). What makes matters worse is that project aid tends to be the dominating aid modality in those countries with the weakest capacities, such as fragile states.

3 A 2006 compendium of first experiences and emerging lessons of the instrument published by the World Bank (Koeberle et al. 2006) describes budget support as an aid instrument with the following characteristics: (i) channeling of donor funds to a partner country using its own allocation, procurement, and accounting systems; (ii) support for a recipient country's own development programmes, typically focusing on growth, poverty reduction, fiscal adjustment, and the strengthening of institutions, particularly the budgetary processes; (iii) policy content, performance assessment, and an accountability framework that focus on policy measures and benchmarks related to overall budget and policy priorities, as set out in the country's own poverty reduction strategy and medium-term expenditure framework; (iv) provision at regular intervals, ideally in alignment with the country's annual budget cycle; and (v) agreement on general budget priorities and expenditures, so that in principle there is no need to earmark funds for specific items. 
In essence, budget support is hoped to make aid more effective by

- reducing transaction costs for the government by avoiding parallel project and reporting arrangements;

- increasing the predictability of funding;

- addressing cross-cutting government-wide policy, expenditure, and institutional priorities that cannot be tackled with stand-alone and sector projects;

- promoting government accountability, both internal (to parliament and taxpayers) and external (to donors);

- improving the efficiency and transparency of budget spending, reducing the fragmentation of public expenditure management, and integrating recurrent and capital expenditures;

- buttressing the recipient country's own budget process and public financial management; and

- encouraging a greater orientation to medium-term results by focusing on national development objectives rather than on donor-driven priorities, operational issues, or activities with limited scope and effect (Koeberle and Stavreski 2006: 7ff.)

Notwithstanding the plausibility of at least some of these arguments, the move by various donors to provide budget support to developing countries has met significant criticism within the aid community as well as the wider public in donor countries. In particular, opponents of the approach argue that aid given in the form of general budget support is fungible money (cf. Morrissey 2006: 339) and as such prone to unacceptably high fiduciary risks, ${ }^{4}$ meaning that in most cases aid money will end up in the pockets of corrupt government officials (cf. Kolstad 2005) or financing things unwarranted by taxpayers in the donor countries.

Although it is disputed whether the fungibility of aid resources is really something donors should be particularly worried about (see Box on next page), and despite the fact that recent evaluations of budget support programmes have not produced evidence that fungibility negatively affects the effectiveness of budget support in practice, ${ }^{5}$ the concern about fiduciary risks of aid has inspired the search for aid instruments that can ensure that recipients use the provided resources in line with donor preferences, but without bearing with the disadvantages of traditional project aid.

4 Fiduciary risk in the context of development aid describes the risk that aid resources are not (or not efficiently) used for the purposes intended by the donor (cf. DFID 2009: 4, de Kemp et al. 2011: 40).

5 A international evaluation effort of budget support comprising of seven country case studies finalised in 2006 found improvements of public financial management in budget support receiving countries (IDD and Associates 2006). More recent pilot evaluations testing a newly developed 'comprehensive' evaluation approach (Caputo et al. 2008) in Mali, Tunisia, and Zambia have found some evidence for a crowding-in or 'flypaper' effect of budget support, whereby expenditure in sectors prioritized by donors in their policy dialogue and performance assessment (such as health and education) increased by larger amounts than what was received in budget support (Caputo and de Kemp 2011: 17). This, of course, does not automatically imply better development results as donor preferences may well be less development oriented than recipient governments' preferences. 
Box 1: Fungibility - concept and empirical foundation

The idea that aid resources are fungible is far from new and has been a donor concern as early as the 1950s when, reportedly, the World Bank's first Chief Economist Paul Rodenstein-Rodan noted that even when financing was tied to projects, money often remained fungible (World Bank 1998: 82).

This fact notwithstanding, the term fungibility is sometimes used in a somewhat confusing manner in the aid literature: Originally, fungibility describes the property of a resource or good whose units are perfect mutual substitutes, the textbook example being money. Applied to aid resources, this translates to the idea that aid resources intended to finance some particular expenditure can be used to finance something entirely different. In the aid literature, however, the term is commonly used to describe the fact that (or the degree to which) resources actually are re-allocated from the intended to an unintended use, which evidently is not entirely the same thing. ${ }^{6}$

Morrissey (2006: 334) distinguishes three elements of fungibility: general fungibility, which arises where aid intended for a general purpose is used for another (for instance consumption instead of investment expenditure); categorical fungibility, describing the use of aid intended for a particular sector or budget heading for another (e.g. defense instead of health); and (non-)additionality, which describes the possibility that even if aid resources are used for the intended expenditure, they might free up the recipient government's own (tax) resources allocated to that area to be used elsewhere so that allocations to the intended purposes do not increase by the full amount of aid.

In a more generic definition, White and Dijkstra (2003: 468) define fungibility as "the idea that aid pays not for the items which it is accounted for but for the marginal expenditure it makes possible". Importantly, in principle this applies to all forms of aid, because even if donors fund the desired activities directly, this may free up domestic government resources to be spent on different uses (Zampelli 1986: 33; McGillivray and Morrissey 2000: 423). ${ }^{7}$ This possibility is indeed a serious concern for donors (Sobhee 2009), and theoretical arguments (e.g. Pack and Rothenberg Pack (1993)) as well as empirical evidence (e.g. Feyzioglu et al. (1998), Devarajan et al. (1999), Lu et al. 2010) support the view that most aid is indeed highly fungible at sector level, meaning that aid earmarked for particular sectors is diverted according to government preferences.

More recently, however, a number of authors have argued that fungibility is not necessarily a bad thing nor something donors need to be particularly worried about with regard to aid effectiveness (e.g. Hauck et al. 2005, Rothmann and ten Have 2004, Pettersson 2007, McGillivray and Morrissey 2000, 2004, Wagstaff 2011), proposing that 'in countries with sound policies, appropriate allocations of expenditure, and effective services, donors can provide large amounts of assistance as general budget support, knowing that the resources will be well used.' (World Bank 1998: 61). According to this perspective, fungibility per se is not a relevant issue but how aid affect fiscal behaviour and the effectiveness of public spending (McGillivray and Morrissey 2004: 81, Morrissey 2006: 335,343).

It is in this context that the latest addition to the donors' toolbox in the form of so-called results-based approaches (or 'aid on delivery' - AoD) has surfaced. While it seems that no broadly accepted terminology has evolved in the debate on results-based aid so far and there is thus no commonly accepted definition yet, the key feature of results-based aid or $\mathrm{AoD}$ is that this form of aid is disbursed proportional to the achievement ('delivery') of pre-defined outcomes (e.g. school enrollment) by the recipient (cf. Klingebiel 2012: 7, Birdsall et al. 2010: 2). ${ }^{8}$

6 For an insightful discussion of the somewhat 'sloppy' use of the term in the aid literature, see O. Barder's blog on http://www.owen.org/blog/3224 (accessed 16.4.2012).

7 One effect that potentially counteracts fungibility is the so-called 'flypaper' effect, i.e. the empirical observation from studies of fiscal federalism that money 'sticks where it hits' (Singhal 2006:1) or, in a slightly different interpretation of the term, that expenditure of recipient tiers of inter-government grants increases by more than the amount of the grant (Barnett 1993, quoted in McGillivray and Morrisey 2000: $420)$.

8 Although the more common term is results-based aid (RBA), in this paper we prefer to use the term aid on delivery (AoD) to emphasize this key feature of the proposed approaches. 
The main purpose of this approach is to avert fiduciary risks and ensure that donor money is used appropriately (World Bank 2012), i.e. to fund expenditure prioritized by donors, but without donors getting directly involved in implementation. Given that there is no direct earmarking of the disbursed funds themselves (cf. Birdsall and Savedoff (211: 18), in essence, AoD is a form of budget support based on a contract between donor and recipient on the delivery of agreed (measurable and continuous) outcomes which are then 'rewarded' by the donor according to a 'unit price' attached to these outcomes. ${ }^{9}$

AoD approaches have received considerable attention lately, with numerous bi- and multilateral donors piloting programmes in different countries and sectors (Klingebiel 2012: 18, BIC 2012), yet to date no comprehensive evaluations as to the effectiveness of the approach have been undertaken.

Nonetheless, the general view among many policy makers as well as researchers (e.g. Morissey 2006: 343, Gunning 2006: 298) seems to be that donors can influence much more effectively where their aid is spent when they provide it in the form of projects or AoD, rather than (unconditional or ex-ante conditional) general budget support. This perception has been dominating the political and practitioners' debate on aid modalities of late in a number of donor countries and has led to widespread scepticism towards general budget support as an aid modality (see e.g. Hoven 2009: 1, Leiderer 2010). Yet, while highly relevant in the political debate, the question whether different aid modalities exhibit fundamentally different levels of fiduciary risks and if so, under which circumstances, has so far received little attention in the research on aid effectiveness.

This paper aims to contribute to filling this gap. Specifically, the main questions this paper wishes to address are: (i) whether the fiduciary risk that arises due to fungibility of aid resources really differs fundamentally between aid modalities, in particular in the face of information asymmetries that commonly exist in the donor-recipient relation; and (ii) if it does, what donors can do about it.

Before proceeding to present a simple principal agent framwork in which to analyse these questions, the next section provides a brief overview of some of the literature most closely related to the research questions of this paper, which serves to identify the key elements that should be incorporated in such an analysis.

9 Currently the most prominently discussed approaches to AoD are the Center for Global Development's 'Cash on Delivery' or CoD (Birdsall and Savedoff 2010) and the World Bank's 'Programme for Results' or P4R (World Bank 2011). The European Commission has been implementing an AoD approach within the framework of its budget support operations in the form of performance tranches for a number of years already (cf. Schmidt 2006). 


\section{Fungibility, fiscal response and the political economy of aid: a brief literature review}

Despite the often heated political debate on the 'right' choice of aid instruments and modalities, there is surprisingly scarce work - empirical and theoretical - on the relative effectiveness of different aid modalities.

Consequentially, there is also relatively little empirical evidence or theoretical guidance to inform the debate on how best to provide aid to developing countries. In part, this is due to the lack of a common understanding of what actually constitutes pro-poor or pro-development public expenditure in practice and what does not, ${ }^{10}$ as well as the limited availability of reliable public finance data in the majority of countries for which the question of aid effectiveness matters most. ${ }^{11}$

While there is a fairly large (and still growing) body of research on the macro-economic effects of aid (focusing mainly on aid's impact on growth), ${ }^{12}$ this literature has been criticized for failing 'to explicitly recognize the fact that aid is primarily given to government, and that hence any impact of aid on the economy will be mediated by government behaviour' (McGillivray and Morrissey 2001:1). Some studies attempt to address this and related shortcomings in various ways, for instance by allowing for interaction of aid flows and the quality of state institutions (Burnside and Dollar 2004), by disaggregating aid into components provided with different aims (e.g. Clemens et al. 2004) or in different forms (e.g. Van de Sijpe $2010)^{13}$ and even by explicitly examining the public expenditure transmission mechanism $\left(\right.$ Gomanee et al. 2005) ${ }^{14}$.

${ }^{10}$ Although there obviously are categories of government spending, that are commonly recognized to be most likely pro-poor (Gomanee et al. 2005), in particular health care, education, water and sanitation, housing, social welfare, rural infrastructure, and agricultural research, training and extension (Verschoor 2002).

${ }^{11}$ For discussions of these limitations, see for example Foster and Zormelo (2002), Fozzard (2001), McKay (2002), Roberts (2003).

12 For instance, Mekasha and Tarp (2011) conduct a careful meta-analysis of the results of a large sample of this literature and find evidence for an overall positive and statistically significant impact of aid on economic growth.

13 Building on McGillivray's and Morissey's (2000: 422) earlier criticism that at the same time a large portion of aid does not go through recipient's public sector accounts, Van de Sijpe (2010) proposes an analytical framework to distinguish between on-budget and off-budget aid, arguing that not accounting for the fact that a large share of aid is not recorded in the recipient government's budget may lead to biased estimates of the extent of fungibility of aid. The empirical analysis employed to test this model finds little evidence to suggest that aid is fully fungible. At the same time, Van de Sijpe (2010) is not able to ascertain if the degree of fungibility differs by aid modality, using technical cooperation as a proxy for off-budget aid. However, in times of increasing pressure on donors to make their aid transparent, this might not be a fully adequate proxy for off-budget aid. It is arguably less the fact whether aid resources are channeled through the recipient's own expenditure procedures, than whether these resources are recorded in the budget and thus can be taken into account in the overall allocation decisions. In fact, there is a useful distinction to be made between 'on-budget' and 'through-budget' aid resources. While through-budget implies the use of government's own public expenditure management systems in making use of the provided aid resources, on-budget merely requires the recording of aid resources in the budget document in order to provide government, parliament and the public with a more adequate picture of the overall allocation of resources.

${ }^{14}$ Gomanee et al. (2005) include an index for 'pro-public expenditure' in their estimations of aid's impact on welfare indicators. However, while they do find a positive impact of aid on aggregate welfare, they do not find evidence that this impact works through the pro-public expenditure transmission channel (Gomanee et al. 2005: 364). 
Nonetheless, this strand of research is primarily concerned with the aggregate macroeconomic impact of aid and eventually with role government fiscal behavior and other transmission channels play for this impact. It does not look at the impact aid (and in particular different forms of aid) has on the transmission channels themselves. As a result, this literature offers little guidance to inform the donors' choice of aid modalities.

\section{$2.1 \quad$ Fungibility and fiscal response analysis}

There is a different - somewhat smaller - body of empirical research, however, that does explicitly study the impact of aid on public expenditure and fiscal behavior in recipients countries. In essence, two main strands of research with this particular focus can be distinguished in the existing literature: The first, commonly subsumed under the term fungibility studies, is primarily concerned with identifying whether aid that donors intend to spend on particular expenditure items or sectors is in fact allocated to those areas (see Box 1 above). In a second strand, the fiscal response literature explicitly models and empirically tests how the impact of aid is mediated by public sector behavior. These models focus on the timeseries impact of aid on fiscal aggregates, taking into account not only spending decisions but also the effects of aid on other fiscal policy measures such as tax effort and public borrowing (McGillivray and Morrissey 2001a: 1; McGillivray and Morrissey 2004: 83).

In a critical review of both strands of research, McGillivray and Morrissey (2001a) conclude that fungibility studies are generally too narrowly focused on partial and static analysis of the composition of government spending and are not sufficiently informative on behavioral questions, mostly because they tend to focus on testing if fungibility actually exists, but do not offer rigorous explanations of why it occurs (Lahiri and Raimondos-Moller 2004: 213).

More specifically, McGillivray and Morrissey (2004) identify four main limitations of categorical fungibility studies: (i) the underlying theoretical model posits that only fungible aid affects governments' spending decisions and does not allow aid to affect allocation decisions across expenditure headings; (ii) there is a lack of data on donors' intentions to fund particular sectors or programmes; (iii) the applied econometric techniques are insufficient as they assume that the different components of government spending are determined not jointly but independently; and (iv) fungibility studies ignore the broader fiscal dynamics affected by aid, such as the impact on taxation and government borrowing (Morrissey 2012: 3).

Notwithstanding these important limitations, as Morrissey (2012: 3) notes, some unwarranted conclusions have been drawn from this literature, notably that fungibility 'helps explain why large amounts of aid have had no lasting effect in highly distorted environments' (World Bank 1998: 82).

In comparison, fiscal response studies are broader in scope, as they attempt to identify how aid may induce government behavior that undermines or enhances the positive impact of aid. However, these models are deemed 'notoriously difficult to estimate, and highly sensitive to (and demanding of) the quality of the data.' (McGillivray and Morrissey 2001a: 18). Moreover, fiscal response models require estimates of expenditure and revenue targets; yet - as 
McGillivray and Morrissey (2001a) stress - there is no generally accepted theory regarding how governments form such targets.

As a result of these theoretical and empirical limitations, McGillivray and Morrissey (2001a: 25) conclude, there is little evidence emanating from either fungibility or fiscal response studies as to the question whether over time aid leads to an increase in expenditures that promote growth and poverty-reduction.

Consequently, these strands of empirical research do also not provide sufficient evidence on which to base donors' choice of instruments and modalities to provide aid to developing countries.

\subsection{Political economy analysis and aid effectiveness}

In the absence of robust empirical evidence on the relative effectiveness of different forms of aid it is arguably even more important to establish a solid theoretical basis with regard to the underlying mechanisms that have the potential to impact on the effectiveness of aid. In particular, to inform policy decisions on which aid modalities to choose in specific circumstances, it would appear necessary to get a better understanding of how different types of aid and conditionality affect incentives for recipient governments to allocate domestic as well as externally provided resources between competing uses.

In line with this argument, some of the more recent theoretical literature on the effects of aid on government expenditure has focused on the political economy underlying public resource allocation processes in aid recipient countries, mostly based on more generic theoretical models of public finance and special interest politics (e.g. Grossman and Helpman 2001, Grüner 2008), and extending them to include aid donors. ${ }^{15}$ Because 'fundamentally, an analysis of the impact and effectiveness of economic assistance from one nation to another is similar to an analysis of the impact and effectiveness of grants-in-aid in a federal system' (Khilji and Zampelli 1991: 1095), most of this theoretical literature on aid effectiveness also borrows heavily from the voluminous literature on fiscal federalism.

Among the closest to the interest of this paper in this strand of research is Lahiri and Raimondos-Møller (2004), who develop a formal model of aid effectiveness with domestic political competition and an altruistic donor population. Their main result is that the effectiveness of aid (in terms of funding pro-poor public expenditure) is undermined by domestic special interest politics in the recipient country: In their model, aid leads to more intense lobbying by one of the interest groups, which in turn leads to a lower proportion of aid reaching the poor. However, Lahiri and Raimondos-Møller's model does not explicitly incorporate aid conditionality nor any other form of differentiation between aid instruments, and thus does not provide a satisfactory answer to the question whether different forms of aid transfers and conditionality can be expected to differ with respect to their effectiveness.

${ }^{15}$ For an extensive review of the more generic literature on the political economy of public finance see Persson and Tabellini (1999). 
One related paper that does explicitly account for the impact of aid conditionality on government decisions is Hefeker and Michaelowa (2003), who analyze the effectiveness of process conditionality, modeled as changing the way the welfare of the poor population enters the government's utility function. They find that this type of conditionality is only effective when donors hold all necessary information. If they do not hold this information or if other bureaucratic interests reduce their incentive to acquire information, process conditionality loses its effectiveness in achieving the desired objective to induce domestic policies beneficial to the poor.

The model by Hefeker and Michaelowa, however, neglects another potentially important influencing factor on aid effectiveness, namely the degree of aid dependency. The recipient government in the model does not receive any domestic revenue, and fungibility thus only occurs in the form that aid resources can be used to influence a one-dimensional policy distortion that's strictly bad for the poor and the donors. Moreover, the model by Hefeker and Michaelowa (2003) does not incorporate any form of performance or outcome conditionality.

One model that does incorporate aid dependency as a factor with the potential to impact on aid effectiveness is suggested by Cordella and Dell'Ariccia (2007), who directly compare the effectiveness of project aid versus (conditional) budget support that can be spent either on developmental expenditure or alternative uses (e.g. military expenditure). They conclude that 'the relative effectiveness of these two forms of aid depends on the size of the aid programme (relative to the recipient government's own resources) and on the degree of misalignment between the objectives of donors and recipients' (Cordella and Dell'Ariccia 2007: 1261). ${ }^{16}$

Hefeker and Michaelowa (2003) and Cordella and Dell'Ariccia (2007), therefore, both provide valuable insights into the research question at hand. Yet, they do not differentiate between different forms of budget support (such as GBS and AoD) as applied in practice, which is the particular interest of this paper.

Another model that does incorporate different forms of budget support conditionality is Hefeker (2005), who compares unconditional budget support, project aid, and conditional budget support, and extends the analysis by introducing the self-interest of the donor agency. Assuming the three aid modalities are subject to varying degrees of corruption, Hefeker (2005) finds that the relative effectiveness of the aid instruments depends on the degree of aid dependency of the recipient country and that - for a low degree of aid dependency the income of the poor is higher with conditional budget support than with unconditional. Hefeker (2005) also shows that the relative effectiveness of aid instruments depends on the degree of misalignment between donors' and recipient governments' preferences.

${ }^{16}$ In their model, Cordella and Dell'Ariccia (2007) assume that budget support can in part be conditioned upon development spending by the recipient government. More precisely, Cordella and Dell'Ariccia (2007) assume that aid (and government's own resources) can be used to produce a developmental good out of two inputs capital and managerial / administrative outlays. Donors can only observe and make aid conditional upon government's outlays on the capital component of the development programme (Cordella and Dell'Ariccia 2007: 1265). 
However, these results in part depend on project aid always being fully fungible in the model, based on the assumption that the aid budget will not be larger than the government's own (financed from domestic sources). The empirical evidence for a number of typical aid recipient countries, in particular in sub-Saharan Africa, however, suggests otherwise. ${ }^{17}$ Thus, while generating some valuable insights with respect to the relative effectiveness of different aid modalities, this model does not consider one of the aid modalities of particular interest here (AoD) and is partly based on assumptions that do not necessarily apply to some countries for which the effectiveness of foreign aid is most relevant.

Yet another model that explicitly incorporates performance- or outcome-based conditionality in a principal-agent framework is Ivanova (2006), who - building on a model developed by Mayer and Mourmouras (2001) - finds that outcome-based conditionality may be a good option when the opposition by a self-interested lobby is relatively weak and where performance is relatively easily and unambiguously measurable. In comparison, the effectiveness of outcome-based conditionality in the presence of strong opposition by special interest groups is less clear, in particular if these groups extract significant rents and can offer the government a 'bribe' that outweighs the value of external financing (Ivanova 2006:20). Similar to Michaelowa and Hefeker (2005), however, the government in this model does not explicitly decide on the use of public resources, but sets a one-dimensional distortionary policy. Hence, this specification does not provide for a direct comparison of different aid modalities' impact on government expenditure. In addition, the results of the model hinge on the assumption that aid is given as a loan, which is not the case for most real world budget support operations. ${ }^{18}$

One of the most recent papers in this stream of research to our knowledge is Jack (2008), who models two developing countries' governments' simultaneous decision to allocate aid receipts by a single donor to social sector expenditure that can be used to serve either a small elite or the poor, and to more traditional public goods, which are non-competitive in consumption and thus benefit both groups equally. Jack (2008) examines how the donor's influence on the government's allocation decision varies in the face of conditional aid and when information asymmetries are introduced into the model. The paper finds that optimal conditionality, which maximizes the utility of a perfectly altruistic donor induces 'good' (i.e. pro-poor) governments to spend too much on public goods, 'bad' (i.e. pro-elite) governments too little, in the case where both governments care relatively little about poverty; when both governments are relatively poverty-averse, 'good' governments spend too much on social services and 'bad' governments too little.

Yet, as in Michaelowa and Hefeker (2005), the results by Jack (2008) depend on the important simplification that the recipient governments do not command any domestic revenue and depend entirely on external aid to finance their budgets. ${ }^{19}$

\footnotetext{
${ }^{17}$ In highly aid dependent countries, in particular in Sub-Saharan Africa, aid as a percentage of central government expenditure can exceed 100 percent (McGillivray and Morrissey 2004: 73).

${ }^{18}$ In general, bilateral donors as well as the European Commission provide their budget support as grants.

19 Jack (2008) justifies this simplification with the argument that the share of aid in budgets of many countries
} 
Therefore, this model also cannot account for an important aspect of aid fungibility, namely that external resources, even if not directly deviated, can free up government resources to fund expenditure items unwarranted by the donors.

One model that does allow for this type of 'indirect' fungibility is developed by Azam and Laffont (2003), who analyze aid as a contract between an altruistic North and a rich local elite in the South, where poverty reduction in the South is regarded as an international public good. They examine the optimal contract when there is information asymmetry with regard to the Southern elite's degree of altruism. Although not an explicit comparison of different aid modalities' fungibility, the optimal contract for the donor in the model takes the form of AoD that is provided conditional on the observed consumption of the poor. From the donor's perspective this aid modality is clearly preferred to unconditional aid in this model. However, the result hinges on the particular form of the utility functions, which lead to unconditional aid being fully captured by the local elites (the rich in the South) and the optimal contract taking the form of performance-based aid disbursed conditional on the observed consumption of the poor. The poor themselves have no political representation but only enter the utility function of the rich who also provide the government. This is obviously a fairly restrictive assumption, putting in question whether the findings should be directly applied to real world policy decisions. ${ }^{20}$

Finally, another study that also explicitly addresses the effects of different forms of aid on fiscal behaviour in recipient countries, is McGillivray and Morrissey (2001b), who examine explanations for flypaper effects in a simple static microeconomic model. The authors demonstrate in a number of theoretical scenarios how misperceptions or illusions about the real value of aid provided in different forms can lead to increasers in total public expenditure greater than the actual inflow of aid resources. While this study is primarily concerned with the effect of misperceptions about the real or nominal value of aid inflows and not fungibility or fiduciary risk as such, the simplicity of its analytical framework is compelling and would seem a good starting point to understand some of the fundamental mechanisms at work under different aid modalities with regard to allocation decisions. In particular so, because the different forms of aid provision examined by McGillivray and Morrissey (2001b) are essentially equivalent to project aid, general budget support and aid on delivery.

\subsection{Research gap}

In sum, while providing valuable insights into some of the political economy mechanics at work when providing aid, none of the described studies seem to give a satisfactory answer to

in Sub-Saharan Africa is sufficiently large that fungibility issues should not be relevant in practice. Yet, even in a highly aid dependent countries such as Burkina Faso where aid as a percentage of central government expenditure amounted to 108.9 per dent in 2005, aid as a share of gross national income was an average 5.5 percent in the same year. This compares to tax-to-GDP ratios in the region between 6.9 percent (DR Congo) and 38.6 percent (Botswana), which suggests that even in extremely aid dependent countries, there remains considerable scope for a crowding out of domestically financed expenditure by aid resources (Data Sources: World Bank (2007), AfDB and OECD (2005)).

${ }^{20}$ Most (if not all) budget support is provided to countries that at least have some form of - even if imperfect - multiparty democracy. 
the questions this paper wishes to address, namely i) whether the fiduciary risks that arise due to fungibility of aid resources really differ fundamentally between aid modalities, in particular in the face of information asymmetries that commonly exist in the donor-recipient relation; and (ii) what donors can do about it.

Given poor data availability and limited knowledge about what makes government expenditure pro-poor, empirically evaluating the relative effectiveness of different aid modalities will remain a challenging - if not impossible - task in the near future.

At the same time, the theoretical economic literature so far also does not provide a conclusive argument in favor of or against 'new' aid modalities such as general budget support or aid on delivery. This is mainly because the key question in this context has not been adequately addressed, namely whether different forms of aid really differ in their degree of fungibility, or, more specifically, whether some aid modalities (such as project-based aid or aid on delivery) really give donors more control over the use of the provided resources than others (in particular general budget support) and can thus help to make recipient governments' allocation decisions more development or poverty-reduction friendly.

This shortcoming is partly due to the fact that existing models of the aid relationship fail to incorporate some important potential determinants of a differentiated impact of alternative aid modalities on recipients' allocation decisions. As the review of some of the most closely related theoretical literature on the topic suggests, such an analysis should incorporate as a minimum:

- different types of conditionality/aid modalities

- motivated recipient government preferences (e.g. as the outcome of political contest of domestic interest groups)

- aid dependency

- government commitment to poverty reduction, and

- information asymmetries.

In the remainder of this paper a basic model is presented that attempts to incorporate all five of these elements in a simple principal-agent framework of the aid relation in face of different aid modalities.

\section{A basic fungibility model of aid modalities}

The provision of aid for poverty reduction or other development objectives can be framed as a series of principal-agent relations. In a simplified way, this is illustrated in Figure $1 .^{21}$ The common conception is that donor governments (mostly - but not exclusively - Western democracies) provide aid on behalf of their own constituencies, out of altruistic and/or other motives of the tax payers or interest groups they represent. In most cases, however, donor governments do not implement aid programmes themselves, but mandate dedicated

${ }^{21}$ See for example Easterly (2006) and Gibson et al. (2006) 
implementing agencies to do so. At least in the case of budget support, these aid agencies in turn then rely on recipient governments to make use of the resources provided in the intended way. At the same time, recipient governments act as agents for their own constituencies of tax payers and special interest groups. Aid recipient governments thus commonly act as agents in a multitude of principal-agent relations when they decide how to allocate public resources generated from tax revenue, aid, and other sources.

Figure 1: Simplified agency framework of the aid relation

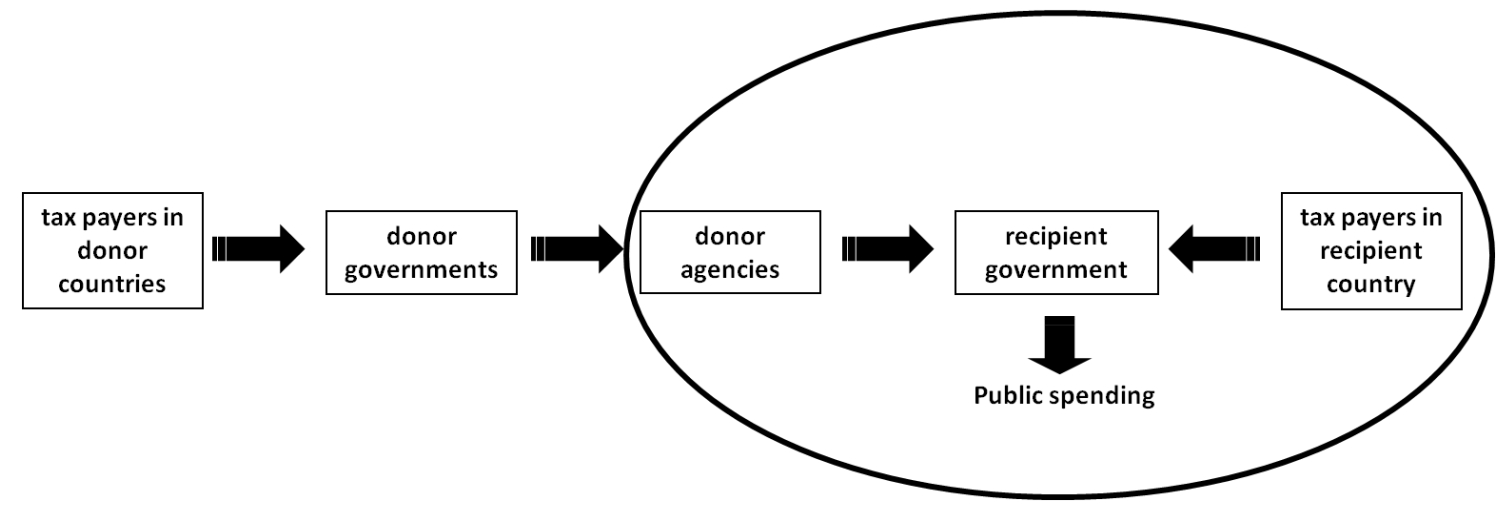

Source: Author's illustration

The interest of this paper is to examine the extent of fungibility in the case of different forms of budget support as compared to project-based aid. For this analysis, we focus on the central section of the common agency setting for the recipient government, highlighted in Figure 1. ${ }^{22}$ In the following sections we develop a very basic model of aid modalities in what can be interpreted as a common agency framework. This then serves to analyze how fungibility and information asymmetries affect government choices under different aid modalities to allocate domestic resources and aid receipts to competing uses.

Note that the main interest of this paper is not to devise any particularly effective or efficient aid mechanism, but to analyze real world proposals made by donors with regard to their potential effectiveness. The main purpose is to examine the influence of fungibility and information asymmetry on the effectiveness of different aid modalities in as simple a setting as possible. For this reason, we employ a very simple static standard microeconomic analysis, which for obvious reasons bears many similarities to earlier work on related questions. In particular the graphical illustrations of the basic case borrow heavily from McGillivray and Morrissey (2001b). ${ }^{23}$

22 This does not not imply that the other agency relations depicted are of lesser importance to the issue of aid effectiveness. To the contrary, a number of eminent authors such as Martens et al. 2002, Easterly (2006) or Gibson et al. (2006) argue that the effectiveness of aid is strongly affected by the principal-agent relation between governments and their aid agencies.

${ }^{23}$ As described in the brief literature review in the previous section, McGillivray and Morrissey essentially analyze the same aid modalities that we are interested in here but with a view to explaining how aggregate spending increases in excess of aid inflows can be explained. 


\subsection{Preferences}

We assume a simple one-period setting in which there are only two interest groups in the developing country (the 'rich' and the 'poor'). We further assume that it is known how government expenditure translates into poverty reduction and that expenditure aimed at poverty reduction can be perfectly distinguished from expenditure serving other purposes. Therefore, the developing country's government can allocate its budget between pro-poor expenditure ppe, which only benefits the poor, and an alternative good $x_{0}$ that only benefits the local elites (the 'rich').

For the sake of simplicity, it is assumed that both the poor and the rich benefit directly (and linear) from the resources the government allocates to $p p e$ and $x_{0}$ respectively, so that the welfare function of the poor can be described by

$$
W^{P}=\text { ppe }
$$

and that of the rich by

$$
W^{R}=x_{0}
$$

Following Hefeker/Michaelowa (2003) we assume that both interest groups provide the government with political support (rather than material gifts). The political support accorded to the government directly depends on the amount of public funds allocated to the respective group's benefit.

It is furthermore assumed that this political support translates into government preferences over the welfare of the poor and the rich, which take the form of a CES utility function ${ }^{24}$ and can thus be expressed as a direct function of ppe and $x_{0}$

$$
W^{G}=p p e^{\Theta} \cdot x_{0}^{(1-\Theta)}
$$

where

$$
0<\Theta<1
$$

describes the relative weight the government assigns to the welfare of the poor relative to that of the rich, or - in other words - its (relative) commitment to poverty reduction. ${ }^{25}$

24 This functional form for the government's utility function implies that in a $p p e, x_{0}$-diagram, all loci where the government's indifference curves have an identical slope lie on a straight line through the origin.

${ }^{25}$ Note that this restriction on $\Theta$ implies that the government never completely ignores the welfare of either of the two interest groups. Although the results of this analysis do not decisively hinge on this restriction, it can be safely assumed that this is a realistic assumption for most countries, where complete denial of one or various interest groups could lead to social unrest and the removal of the government. Moreover, while the political contest presumably underlying the shape of the government's utility function will not play an explicit role in the further analysis, we explicitly chose this motivation to make the point that government commitment is a function of internal and external incentives and not some unalterable exogenous factor, as sometimes suggested in donor rhetoric. 
Let us assume that under autarky (i.e. in the absence of foreign aid) the government receives lump sum domestic revenue $Y .{ }^{26}$ Solving the government's maximization problem given by Equation (3) subject to the budget constraint ppe $+x_{0} \leq Y$ then yields the government's optimal allocation decision under autarky

$$
p p e^{a}=\Theta Y
$$

and

$$
x_{0}^{a}=(1-\Theta) Y .
$$

This allocation decision is depicted in Figure 2 where the straight line $t_{\Theta}$ indicates all loci where - for a given $\Theta$ - the government's indifference curves have the same slope as the autarky budget constraint. The indifference curve $u_{1}$ indicates the government's utility in this allocation point in terms of the political support from the two interest groups it generates.

Figure 2: Allocation under autarky

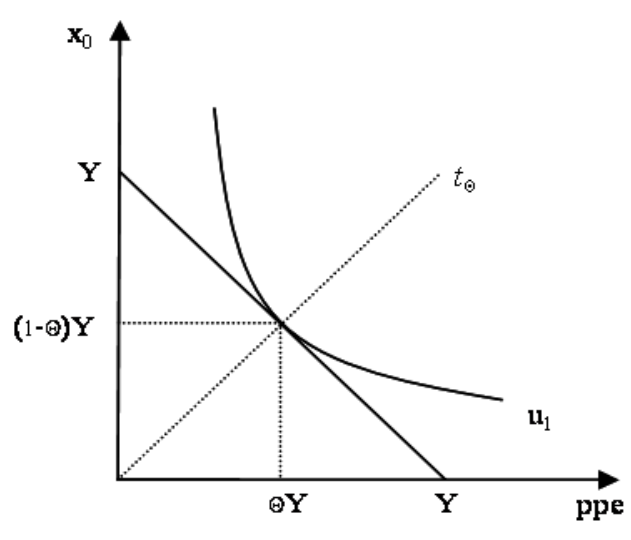

Source: Author's illustration

Now assume that the government receives foreign aid $T$ from a perfectly altruistic donor (i.e. whose sole interest is to increase ppe in the recipient country) with a fixed aid budget $A$. For the sake of simplicity, we assume the donor is indifferent to the level of $x_{0}$ chosen by the recipient government ${ }^{27}$ and that her utility only depends on the amount spent on ppe.

The donor's utility function can thus be written as

$$
W^{D}=p p e
$$

26 This obviously is an important simplification as it implies that no crowding out of domestic revenue can occur in our model.

${ }^{27}$ In practice, this need not always be the case. It is easily conceivable that certain expenditures, such as military spending or certain types of government consumption, would be considered a 'bad' by the donor. For this analysis, however, we abstract from this complication. 
and the government maximization problem becomes

$$
\max W^{G} \quad \text { s.t. } \quad p p e+x_{0} \leq Y+T
$$

Since the main aim of this paper is to compare the relative effectiveness of different aid modalities to induce pro-poor expenditure in the developing country, the next section introduces different modalities by which the donor can provide her aid to the recipient government.

\subsection{Aid modalities}

The donor has different aid modalities at her disposal. Traditional project aid, unconditional (or strict ex ante conditional) ${ }^{28}$ general budget support (GBS), and performance-based budget support or aid on delivery - AoD. Depending on the chosen aid modality, the aid transfer $T$ takes a different form:

Project aid Assume the donor can use her aid budget $A$ to directly fund poverty-reducing activities in the recipient country, bypassing the recipient's allocation process. For example the donor could directly invest in building schools, hospitals, water and sanitation infrastructure and so forth, or even give direct monetary transfers to the poor. $T$ is given as

$$
T^{\text {proj }}=A=p p e^{d}
$$

where $p p e^{d}$ is the amount spent directly by the donor on pro-poor expenditure items in the recipient country.

General budget support (GBS) Second, the donor can provide general budget support that is directly paid into the recipient government's coffers and not subject to any ex-post conditionality. ${ }^{29}$ This means that the amount of the transfer is fixed and not earmarked for any specific purpose.

Therefore, $T$ in this case is equivalent to

$$
T^{G B S}=A
$$

28 This approach to budget support conditionality reflects for example the World Bank's and the African Development Bank's approach to budget support conditionality. In line with their mandate to provide 'policy-based lending', they make the disbursement of their budget support conditional on so-called triggers and prior actions, i.e. policy measures that need to be taken by the recipient government prior to disbursement. Once these conditions are met, no further conditionality is imposed.

${ }^{29}$ In practice, budget support is rarely given without any conditionality. Some donors (in particular multilateral donors), however, make an effort to tie their budget support only to ex-ante conditions so that once these 'prior actions' are in place, the support is provided free of any further restrictions. It would thus be more precise to talk of budget support with strict ex-ante conditionality. However, for the sake of simplicity we stick to the term of unconditional budget support in this analysis. For an analysis of the effectiveness of eligibility criteria for GBS in the form of prior actions, see Morrissey (2006). 
Aid on delivery (AoD) In practice, various donors make the amount of aid they disburse as budget support conditional on the achievement of outcome indicators that are negotiated ex-ante with the recipient government. The rationale behind this is that in most cases recipient governments will know best how to achieve intended outcomes with the resources available, at least much better than any external actor.

In the simple model we present here, however, the mechanism by which public expenditure is transformed into poverty-reducing outcomes is known to all actors, and thus the donor can directly condition her aid transfer $T^{A o D}$ on the government's own 'autarky' (net of aid) expenditure on $p p e^{a}$ in the form

$$
T^{A o D}=\varepsilon \cdot p p e^{a} \leq A
$$

This aid modality is essentially a matching grant by the donor that directly subsidizes $p p e^{a}{ }^{30}$

\section{The basic case: fungibility with complete information}

The simple structure of this model permits a direct comparison of the relative effectiveness of the different aid modalities with regard to inducing the government to allocate resources to ppe.

To begin with, assume all actors are perfectly informed about all relevant parameters in the model, i.e. on the government's domestic revenue $Y$, its commitment to poverty reduction $\Theta$, and the donor's aid budget $A$. As will become clear, it is useful to choose the unconditional general budget support modality as a baseline to compare the relative effectiveness of the different approaches to aid provision in this model.

General budget support If aid is given in the form of unconditional budget support, the government is then entirely free to spend the transfer $T^{G B S}$ according to its own preferences. Graphically this type of aid simply shifts the government's budget constraint outwards by $\frac{A}{\sqrt{2}}$ (from the origin along the bisectrix) and the optimal allocation will be at the intersection of this new budget constraint with $t_{\Theta}$ in

$$
p p e_{G B S}^{*}=\Theta\left(Y+T^{G B S}\right)=\Theta(Y+A)
$$

and $x_{0}=(1-\Theta)(Y+A)$. This result (illustrated in Figure 3$)$ is in line with the general observation that unconditional aid is entirely fungible, i.e. the government treats this form of aid in exactly the same way as its domestic resources $Y$. It thus uses only a share $\Theta$ of

${ }^{30}$ Note that this formulation implies that the donor subsidizes ppe from the very first dollar spent on poverty reduction. Evidently, the donor could also formulate the AoD contract in a form that it subsidizes $p p e^{\alpha}$ only over and above a certain minimum expenditure level. For the sake of simplicity we do not consider this case in this paper. Also note that in this simple setup, the donor rewards governments own expenditure at a constant rate. This does, however, not imply that the returns to ppe in terms of poverty reduction (or utility of the poor) necessarily need to be constant, but only that the donor (and the domestic interest groups) - knowing the 'technology' by which public expenditure translates into the respective groups' utility - takes any non-linearities into account and rewards government 'effort' at a constant rate. 
the aid transfer $T^{G B S}$ for poverty reduction, while the remainder $(1-\Theta)$ is diverted towards other purposes. ${ }^{31}$

Figure 3: General budget support fungibility

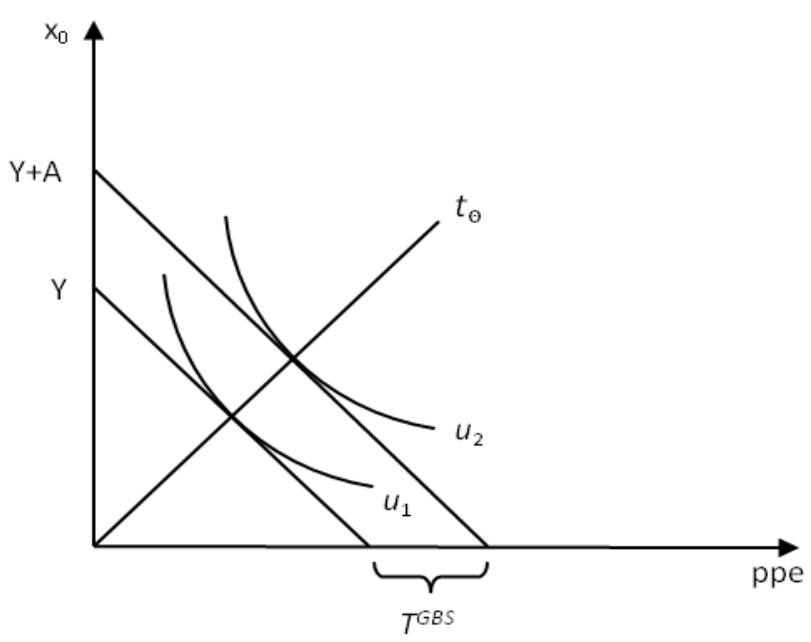

Source: Author's illustration

Project aid In the previous section we made the assumption that project aid can be perfectly conditioned to be spent only on ppe. In this setting, the maximum amount the government can spend on $x_{0}$ is its own revenue $Y$, while the maximum amount it can spend on ppe is $Y+A$. Graphically, this is equivalent to shifting the budget constraint to the right by amount $A$, giving it the shape depicted in Figure 4 .

Figure 4: Fully fungible project aid

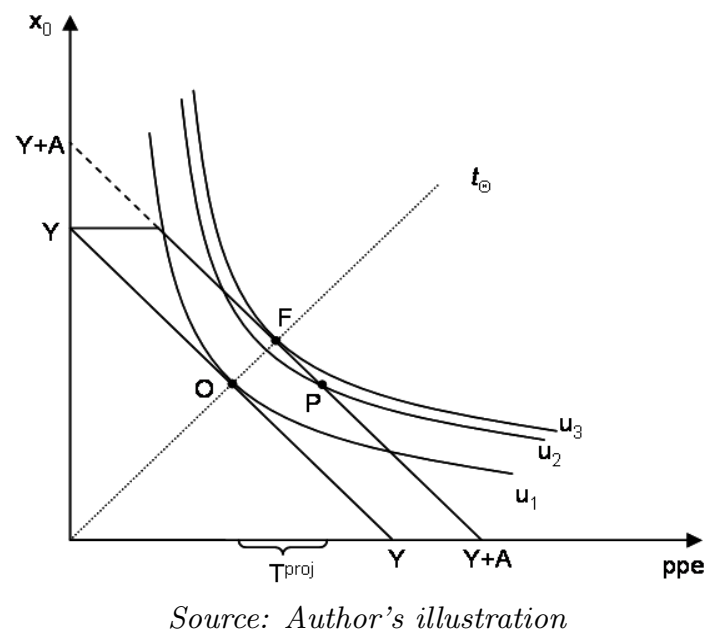

${ }^{31}$ Very similar illustrations of the fundamental fungibility problem can be found in World Bank (1998), McGillivray and Morrissey (2000), van de Sijpe (2010) and others. Most of the particular shapes of budget constraints analyzed in this model are also found in McGillivray and Morrissey (2001b), whose main interest is in explaining how aid can lead to aggregate expenditure rising by more than the value of the aid inflow. Note that in this paper we use the term 'fungibility' in its original sense that fungible resources can be used for other than the intended purposes, and not that they necessarily are. 
As Figure 4 illustrates, in the absence of fungibility, the donor's project expenditure on ppe would simply move the allocation point from the autarky allocation $O$ to the right to $P$. However, the government is clearly better re-allocating part of it's own expenditure from ppe to $x_{0}$, partly offsetting the donor's expenditure and moving to point $F$. Thus, as long as the straight line $t_{\Theta}$ intersects with the new budget constraint to the southeast of the break at ppe $=A$, the resulting allocation in ppe $=\Theta(Y+A)$ and $x_{0}=(1-\Theta)(Y+A)$ is exactly the same as with GBS. This is the case for all $\Theta>\frac{A}{Y+A}$ or, expressed in relation to the degree of the recipient government's aid dependency, $\frac{A}{Y}<\frac{\Theta}{1-\Theta}$.

Only if the aid dependency rate $\frac{A}{Y}$ is high enough (or government commitment $\Theta$ low enough) for $t_{\Theta}$ to intersect with the budget constraint left of the break, does the donor expenditure to ppe become 'binding' for the government. This situation is depicted in Figure 5. It is then optimal for the government to allocate at the break of the budget constraint, allocating all of its domestic revenue $Y$ to $x_{0}$. Pro-poor expenditure $p p e$ in this case would amount to $A$ and be funded entirely by the donor. Note, however, that even in this case, while project aid is evidently not fully fungible, it is also not fully additional, meaning that the total allocation to $p p e$ increases by less than the aid transfer $A$ compared to the allocation under autarky. ${ }^{32}$

Figure 5: Partly fungible project aid

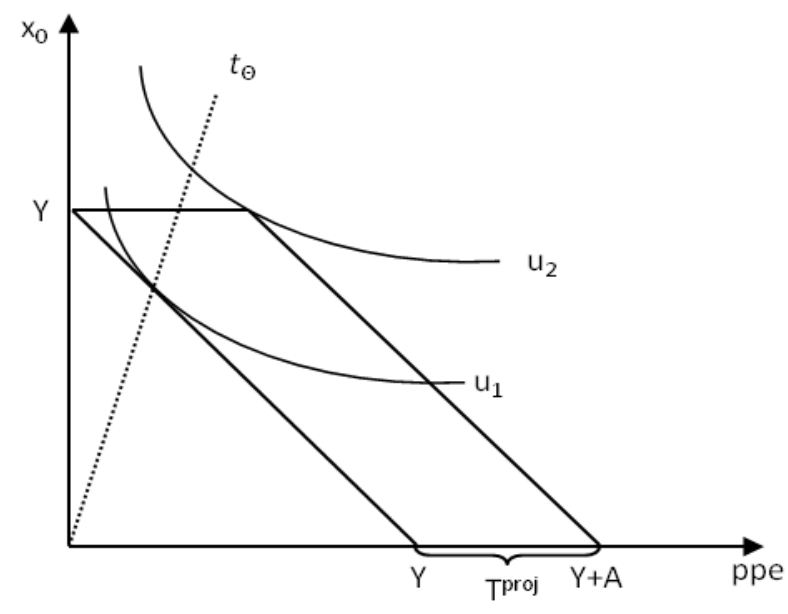

Source: Author's illustration

Therefore, the resulting allocation to poverty-reducing expenditure under project aid is

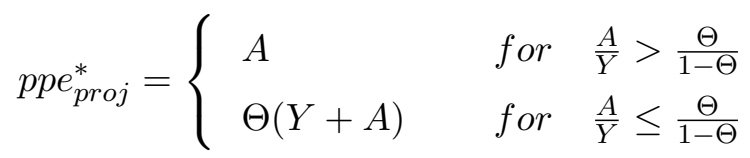

32 This case is described as 'partial fungibility' in World Bank (1998) (see McGillivray and Morrissey 2000: 416). 
and, accordingly, government utility is

$$
W_{\text {proj }}^{G}=\left\{\begin{array}{lll}
A^{\Theta} Y^{1-\Theta} & \forall & \frac{A}{Y}>\frac{\Theta}{1-\Theta} \\
{[\Theta(Y+A)]^{\Theta}[(1-\Theta)(Y+A)]^{1-\Theta}} & \forall & \frac{A}{Y}>\frac{\Theta}{1-\Theta}
\end{array}\right.
$$

In other words, if the government's commitment to poverty reduction is high enough or, vice versa, its dependency on foreign aid low enough, project aid is also fully fungible and, as a consequence, has the same effect as an unconditional aid transfer of the same amount.

Aid on delivery Aid on delivery in the form described in the previous section represents a direct subsidy to the recipient government's expenditure on poverty reduction. In order to analyze the relative effectiveness of AoD, it proves helpful to, first, examine the effect of this kind of transfer if the donor is able to effectively earmark her aid for exclusive use on ppe, before, in a second step, assessing the impact of fungibility on the relative effectiveness of this aid modality.

Assuming AoD funds were not fungible, a transfer in the form described by Equation (10) has the effect of reducing the opportunity cost of allocating to ppe in terms of $x_{0}$, as the government can expand its budget constraint by allocating more of its own resources towards ppe. In other words, the government has to spend a smaller share of its own resources to achieve a given level of ppe than it would have to expend for the same level of $x_{0}$. Graphically, this is equivalent to rotating the autarky budget constraint outwards along the horizontal axis. The optimal allocation from the government's point of view in this situation would be in the point where the rotated budget constraint is tangent to one of its indifference curves, which is in

$$
p p e_{A o D}^{\prime}=(1+\varepsilon) \Theta Y,
$$

Yet, this would imply that the donor can give infinite matching aid. Since the donor's aid budget is fixed at $A$, however, the aid budget might be exhausted before the budget constraint intersects with the horizontal axis, depending on the value chosen by the donor for the matching factor $\varepsilon$. If this is the case, the budget constraint will take the form of the kinked line in Figure 6.

Since for a given $\varepsilon$ the aid budget is exhausted where

$$
\text { ppe }=\frac{1+\varepsilon}{\varepsilon} A,
$$

the government's budget constraint will always have this kinked shape as long as

$$
\frac{1+\varepsilon}{\varepsilon} A<Y+A,
$$

or

$$
\varepsilon>\frac{A}{Y} .
$$


Figure 6: Aid on delivery without fungibility

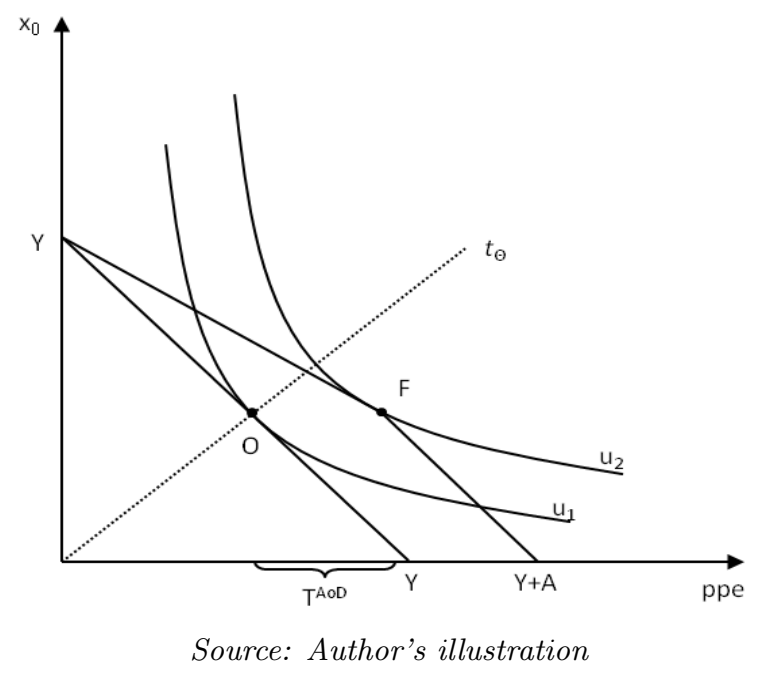

For values of $\varepsilon$ larger than $\frac{A}{Y}$, the government's budget constraint then takes the form

$$
x_{0}=\left\{\begin{array}{lll}
Y-\frac{1}{1+\varepsilon} \cdot \text { ppe } & \forall & \text { ppe } \leq \frac{1+\varepsilon}{\varepsilon} \cdot A \\
Y+A-p p e & \forall & \text { ppe }>\frac{1+\varepsilon}{\varepsilon} \cdot A
\end{array}\right.
$$

Whether for a given $\varepsilon>\frac{A}{Y}$ the government chooses an allocation on the flat or on the steep segment of the budget constraint depends on whether the line $t_{\Theta}$ (representing the loci where the government's indifference curves are tangent to the autarky budget constraint) intersects with the new budget constraint to the left or to the right of of the break of the budget constraint (point $F$ in Figure 6). This depends on whether $\Theta(Y+A)$ is smaller or not than $A \frac{1+\varepsilon}{\varepsilon}$. The government's optimal choice of ppe in view of the donor's choice of $\varepsilon$ is thus given by

$$
p p e_{A o D}^{\prime}=\left\{\begin{array}{ccl}
(1+\varepsilon) \Theta Y & \text { for } \quad \Theta \leq \frac{A}{Y+A} \cdot \frac{1+\varepsilon}{\varepsilon} & \text { or } \quad \frac{A}{Y} \geq \frac{\varepsilon \Theta}{1+\varepsilon(1-\Theta)} \\
\Theta(Y+A) & \text { for } \quad \Theta>\frac{A}{Y+A} \cdot \frac{1+\varepsilon}{\varepsilon} & \text { or } \quad \frac{A}{Y}<\frac{\varepsilon \Theta}{1+\varepsilon(1-\Theta)}
\end{array}\right.
$$

Because condition (17) for a kinked budget constraint also implies that $(1+\varepsilon) \Theta Y>\Theta(Y+A)$, it is best for the donor to choose the matching element $\varepsilon$ so that the government will allocate according to the first section of (19) and choose ppe $=(1+\varepsilon) \Theta Y$. Because this allocation is strictly increasing in $\varepsilon$, it is optimal from the donor's perspective to choose the matching factor $\varepsilon$ as large as possible while ensuring that the government will allocate on the flat segment of the budget constraint. The optimum from the donor's perspective is then for the government to choose $p p e^{\prime}$ on the far right of the flat segment of the budget constraint where the donor's aid budget is just exhausted, i.e. exactly at the break of the budget constraint $F$ in Figure 6 . 
From (15) and the first section of (19), it follows that this is the case if

$$
\varepsilon^{\prime}=\frac{A}{\Theta Y}
$$

which always satisfies (17) as long as (4) holds.

Therefore, as long as the donor can choose $\varepsilon$ according to (20), the allocation schedule (19) simplifies to

$$
p p e_{A o D}^{\prime}=\Theta Y+A
$$

Thus, in the absence of fungibility and as long as there are no restrictions to the magnitude of $\varepsilon$, simple outcome-based budget support is always more effective in inducing ppe than unconditional budget support, since $\Theta Y+A>\Theta(Y+A)$ for all $\Theta$ satisfying (4). Note, that $\varepsilon^{\prime}$ is strictly increasing in the aid dependency ratio $\frac{A}{Y}$. For the extreme case of $\varepsilon \rightarrow \infty$, the first section of the budget constraint becomes horizontal and, therefore, performance-based budget support would become asymptotically equivalent to project support, however, with an infinitesimal higher expenditure on ppe. Thus, in the absence of fungibility, AoD would also be strictly better than project support from the donor's perspective. ${ }^{33}$

Let us now come back to the issue of fungibility. Although AoD is disbursed conditional upon the government's own allocation to ppe, once the aid transfer enters the government's own budget, there is no effective mechanism by which the donor could earmark these funds to be used exclusively for ppe. As a consequence, the government is free to spend any aid received in the form of performance-based budget support on either $x_{0}$ or ppe. In other words, once it is disbursed into the government's coffers, performance-based budget support - or AoD - is fully fungible, just as unconditional budget support. ${ }^{34}$

In the extreme case, the government could allocate all domestic resources $Y$ to ppe and allocate the resulting aid exclusively to $x_{0}$. Therefore, with fungible aid resources the government's effective budget constraint for AoD becomes

$$
x_{0}=\left\{\begin{array}{lll}
Y-(1-\varepsilon) \cdot p p e & \forall & \text { ppe } \leq \frac{A}{\varepsilon} \\
Y+A-p p e & \forall & \text { ppe }>\frac{A}{\varepsilon}
\end{array}\right.
$$

Unlike in the case without fungibility, this effective budget constraint has a kinked shape for all positive values of $A$ and $\varepsilon$. Note, however, that (22) implies that for $\varepsilon=1$ the first segment of the constraint becomes horizontal (as in the case of project aid albeit only to the point where ppe $=Y$ ). For $\varepsilon>1$ it would produce an upward sloping budget constraint for the government up to $p p e=Y$, and falling with a slope of -1 to the East of this point.

33 This is not to say that in practice any donor would be willing to give an infinitely large matching element as part of an AoD contract. This exhibition merely serves to demonstrate the underlying mechanics and limits of the presented aid modalities.

34 The government does, of course, face the restriction that the disbursement of aid depends on its domestic allocation to $p p e^{a}$. As the analysis in the following sections shows, at least in the single donor case it is always in the interest of the government to ensure full disbursement of the available aid budget. 
With complete information, of course, the donor is fully aware of this fungibility problem; and as long as $\frac{A}{Y} \leq 1-\Theta$, she can compensate for it by adjusting the matching element downwards, offering

$$
\varepsilon^{*}=\frac{A}{\Theta Y+A},
$$

which ensures that the effective budget constraint breaks where a government's indifference curve is tangent to the flat segment of the constraint. This in turn ensures that the best choice for the government is to allocate the equivalent of $\Theta Y+A$ from its domestic resources to ppe and use the resulting aid receipts in the amount of $(1-\Theta) Y$ to fund $x_{0}$. In doing so, the donor can induce the same allocation as in the hypothetical case of non-fungible performance-based budget support. This allocation is illustrated in Figure 7, where the dotted line indicates the budget constraint for $\varepsilon^{*}=\frac{A}{\Theta Y+A}$ without fungibility and the solid line the effective budget constraint generated due to the fungibility of the AoD transfer, which is the same as with $\varepsilon^{\prime}=\frac{A}{\Theta Y}$ in the absence of fungibility. In view of the adjusted $\varepsilon^{*}$, the government will allocate a higher amount of domestic revenue to $p p e^{a}$ (point $G$ ) for which it receives aid, which turns the budget constraint outwards to $D$. The government will then, however, use all the aid receipts to fund additional $x_{0}$ and move to point $F$. This re-allocation possibility is shown by the shaded triangle in Figure 7.

Figure 7: Fungible aid on delivery

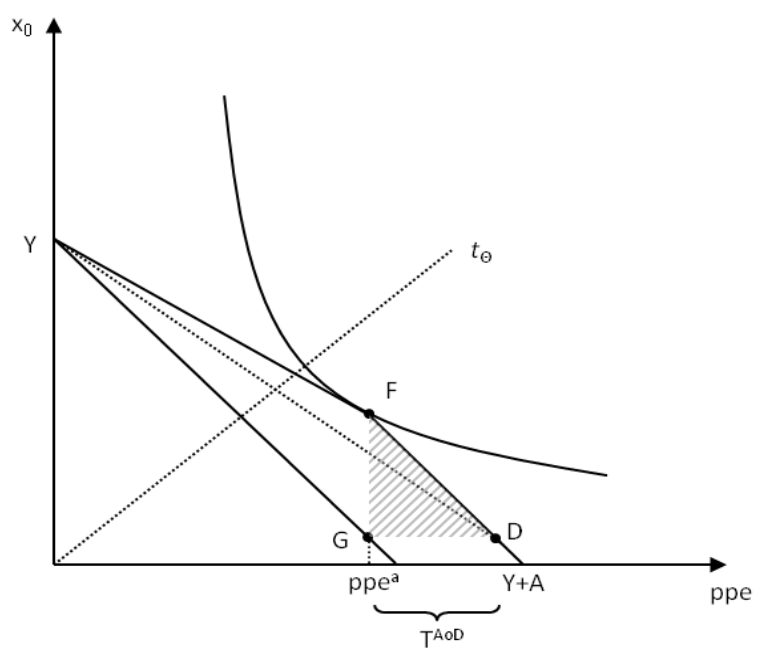

Source: Author's illustration

The figure also shows that by adjusting $\varepsilon$ according to (23), the donor can effectively control for the problem of fungibility in the case of $\mathrm{AoD}$, at least as long as $\frac{A}{Y} \leq 1-\Theta$. However, Equation (23) effectively establishes an upper limit for the matching element of $\varepsilon^{*}<1$ as well as an upper limit for the degree of aid dependency $\frac{A}{Y}$ for which a tangent solution on the flat segment of the budget constraint ensures disbursement of the entire aid budget. This is because for $\frac{A}{Y}>1-\Theta$, offering $\varepsilon^{*}$ does not allow the donor to disburse her full aid budget $A$, even if the government spends its entire domestic resource envelope $Y$ on ppe. 
Under these circumstances the donor would, in principle, have two options: she can either adjust $\varepsilon$ in order to ensure that her entire aid budget will be disbursed or, alternatively, decide to disburse only a share of $A$, should this create more effective incentives for the recipient government.

Let us assume the donor opts for disbursing her entire aid budget $A$. It is then best for her to offer $\varepsilon=\frac{A}{Y}$ and for the government to allocate the entire domestic revenue $Y$ to $p p e^{a} .{ }^{35}$

As long as $1-\Theta<\frac{A}{Y}<\frac{1-\Theta}{\Theta}$, setting $\varepsilon=\frac{A}{Y}$ will ensure an allocation of $p p e^{*}=Y>\Theta(Y+A)$ and would thus, from the donor perspective, still be preferable to unconditional budget support. For values $1-\Theta<\frac{A}{Y}<1$, it would also be preferable to project aid. Figure 8 shows such an allocation. ${ }^{36}$

Figure 8: Aid on delivery with moderately high aid dependency

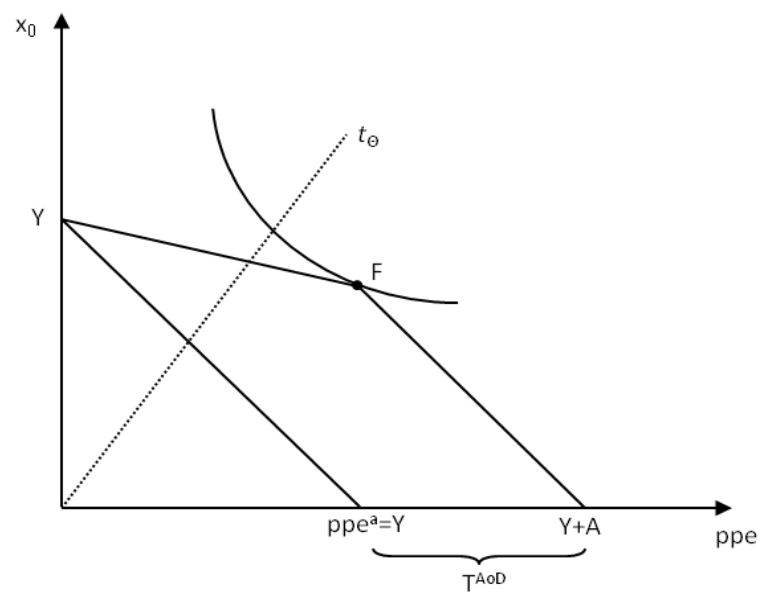

Source: Author's illustration

For $\frac{A}{Y} \geq \frac{1-\Theta}{\Theta}$, however, offering $\varepsilon=\frac{A}{Y}$ allows the government to allocate in $p p e^{*}=\Theta(Y+A)$, which is equivalent to the allocation under GBS and in this case at least as large as $Y$.

Note, that for the special case that the aid budget equals the amount of domestic revenue (i.e. for an aid dependency ratio $\frac{A}{Y}=1$ ) the effective budget constraint for AoD is equivalent to that under project aid as for $\varepsilon=1$ the government's effective budget constraint becomes horizontal up to ppe $=Y=A$ and has a slope of -1 to the east of this point. In turn, for an aid dependency ratio larger than $1, \varepsilon$ would become larger than 1 in order to ensure full disbursement of $A$. This, in effect, would produce an upward sloping budget constraint for the government as described above, up to $p p e=Y$, from where it would again fall with a slope of -1 .

${ }^{35}$ Note, that for the government it is strictly better to allocate all domestic resources $Y$ to $p p e^{a}$ than to allocate less to ppe and forgo aid receipts.

36 Note, that this allocation implies the somewhat perverse result, that domestic resources are used exclusively to fund ppe, while the entire aid budget is used to fund $x_{0}$. 
For values $\frac{A}{Y} \geq \frac{1-\Theta}{\Theta}$ (or $\Theta \geq \frac{Y}{Y+A}$ ), the government would then allocate in ppe $=\Theta(Y+A)$. For $\frac{Y}{Y+A}<\Theta<\frac{A}{Y+A}$ (or $\frac{1-\Theta}{\Theta}<\frac{A}{Y}>\frac{\Theta}{1-\Theta}$ ), this allocation to ppe is then smaller than the aid budget $A$ and, thus, performance-based budget support for these values, from the donor perspective, is inferior to project aid due to the fungibility of the resources. This case is depicted in the left hand graph in Figure 9.

In case $\Theta<\frac{Y}{Y+A}$ (or $\frac{A}{Y}<\frac{1-\Theta}{\Theta}$ ), the best allocation from the government's perspective would be in $p p e=Y$ and $x_{0}=A$. This situation is depicted in the right hand graph of Figure 9.

Figure 9: Aid on delivery with high aid dependency
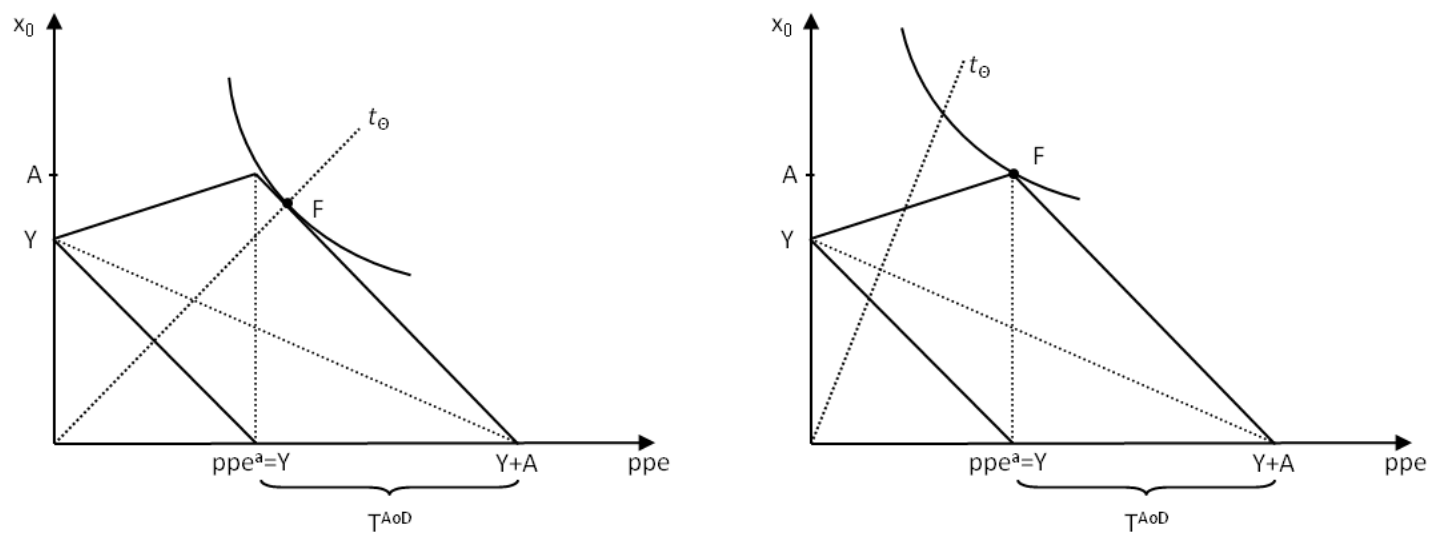

Source: Author's illustration

The results for cases where $\frac{A}{Y}>1-\Theta$ beg the question whether the donor could in these circumstances achieve a better allocation by limiting $\varepsilon$ to some value smaller than $\frac{A}{Y}$ and disburse only a fraction of her aid budget. Clearly, this is not the case for $\frac{A}{Y} \geq \frac{1-\Theta}{\Theta}$ (or $\left.\Theta \geq \frac{Y}{Y+A}\right)$ as the allocation $p p e^{*}=\Theta(Y+A)$ chosen by the government is strictly increasing in $A$ and in this case is also strictly larger than $Y$, the allocation to ppe that could be achieved by limiting $\varepsilon$ to 1 in order to avoid an upward sloping effective budget constraint as depicted in Figure 9 .

For $1-\Theta<\frac{A}{Y}<\frac{1-\Theta}{\Theta}$, however, limiting $\varepsilon$ could be in the interest of the donor, not with regard to effectiveness but in terms of efficiency: Clearly, by reducing $\varepsilon$, it is not possible to induce an allocation to pro-poor expenditure higher than $p p e=Y$. Yet, because pro-poor allocations in this case are independent of the size of the aid budget $A$, the donor can achieve the same allocation at a lower cost, by offering some $\varepsilon=\frac{A^{\prime}}{\Theta Y+A^{\prime}}$ with $A^{\prime}<A$. The smallest $A^{\prime}$ for which this matching element would ensure that the government allocates all of its domestic resources $Y$ to $p p e^{a}$ is $A^{\prime}=(1-\Theta) Y<A$, and thus the most efficient matching element from the donor's perspective would become

$$
\varepsilon^{\prime \prime}=1-\Theta
$$


The reduction of the matching element (and with it of the disbursement of aid), in this case only has the effect to reduce the government's allocation to non-poverty spending, which is $x_{0}=A^{\prime}=(1-\Theta) Y{ }^{37}$

Table 1 summarizes the results of this first step in our analysis. Taking GBS as a benchmark, the results show that - in the absence of transaction costs - the donor should prefer project aid (yielding ppe $=A$ ) over GBS for all combinations of aid dependency and government commitment for which $\frac{A}{Y}>\frac{\Theta}{1-\Theta}$. For all combinations for which $\frac{A}{Y} \leq \frac{\Theta}{1-\Theta}$, the donor would be indifferent between project aid and GBS, inducing $p p e=\Theta(Y+A)$.

Table 1: Aid effectiveness with full information

\begin{tabular}{|l|c|c|c|}
\hline \hline Aid modality & $\begin{array}{c}\text { Aid dependency } \\
\text { Commitment }\end{array}$ & $\begin{array}{c}\text { ppe* } \\
\text { (Donor utility) }\end{array}$ & Government utility \\
\hline \hline GBS & - & $\Theta(Y+A)$ & {$[\Theta(Y+A)]^{\Theta}[(1-\Theta)(Y+A)]^{1-\Theta}$} \\
\hline Project aid & $\frac{A}{Y}>\frac{\Theta}{1-\Theta}$ & $A$ & $A^{\Theta} Y^{1-\Theta}$ \\
& $\frac{A}{Y} \leq \frac{\Theta}{1-\Theta}$ & $\Theta(Y+A)$ & {$[\Theta(Y+A)]^{\Theta}[(1-\Theta)(Y+A)]^{1-\Theta}$} \\
\hline AoD & $\frac{A}{Y} \leq 1-\Theta$ & $\Theta Y+A$ & $(\Theta Y+A)^{\Theta}[(1-\Theta) Y]^{1-\Theta}$ \\
& $\frac{1-\Theta}{\Theta}>\frac{A}{Y}>1-\Theta$ & $Y^{\star}$ & $(1-\Theta)^{1-\Theta} Y^{\star}$ \\
\hline $\begin{array}{l}\text { * Assuming the donor only disburses the amount necessary to achieve ppe }=Y, \text { but ignoring any possible } \\
\text { positive or negative utility derived from undisbursed aid funds. }\end{array}$ \\
\hline \hline
\end{tabular}

A comparison with the the results for AoD shows that the donor should prefer this modality over unconditional GBS for all aid dependency ratios $\frac{A}{Y}<\frac{1-\Theta}{\Theta}$. For $\frac{A}{Y} \geq \frac{1-\Theta}{\Theta}$ she would be indifferent between the two budget support modalities.

${ }^{37}$ Note that in the simple formulation of this model, this efficiency gain is irrelevant, as any unspent aid budget is not an argument in the donor's utility function. Evidently, this could easily be incorporated into the model. Yet, it is by no means clear with what sign any residual aid budget should enter the donor's utility function: One could, of course, argue that any unspent aid could be used to induce povertyreducing spending in other countries, and would thus increase an altruistic donor's utility. However, real world evidence suggest that donor agencies might in fact have strong institutional incentives to act as budget maximizers. In this case, any unspent aid budget could also be negative from the donor agency's perspective. In particular so, if one assumes that outsiders are less well informed about the parameters $\Theta$ and $Y$, and can thus not assess efficiency. Howsoever, the main interest in this paper is with information asymmetries under which the donor does not have this option as will be shown in the next section. Therefore, any possible utility derived from unspent aid resources is ignored at this point. It is important to note, however, there is no way in which the donor could spend the undisbursed aid in the same country (be it as project aid or unconditional budget support) and increase the allocation to ppe. Both modalities would shift the (kinked) effective budget constraint outwards. The fact that in the corner solution $p p e=Y$ the government's indifference curve has a steeper slope than the budget constraint means that the marginal utility of an additional unit of $x_{0}$ is always higher than that of an additional ppe in this range of $\frac{A}{Y}$ and $\Theta$. Therefore, any additional aid disbursed would be exclusively spent on $x_{0}$, independent of the modality through which it is disbursed. 
The donor should prefer AoD over project aid for all $1>\frac{A}{Y}<\frac{1-\Theta}{\Theta}$. For $1<\frac{A}{Y}>\frac{\Theta}{1-\Theta}$, the donor would prefer project aid over AoD. Thus, for $\frac{1-\Theta}{\Theta}<\frac{A}{Y}>\frac{\Theta}{1-\Theta}$, the donor would be indifferent between AoD and GBS, but would prefer project aid over both budget support modalities GBS and AoD.

For values of $\frac{\Theta}{1-\Theta} \geq \frac{A}{Y} \geq \frac{1-\Theta}{\Theta}$ the donor would be indifferent between all three aid modalities, as all three yield ppe $=\Theta(Y+A) \geq A$. In this case the donor has no reason not to give unconditional GBS.

Figure 10 shows the donor's optimal modality choice in an aid dependency / commitment diagram under the assumption that when all three modalities yield the same result, the donor chooses GBS. It clearly illustrates that, under complete information and in the absence of transaction costs, there is no strictly superior aid modality from the donor's perspective. Essentially, which of the three aid modalities should be chosen, depends on the particular combination of aid dependency and government commitment in the recipient country.

Figure 10: Relative affectiveness of aid modalities with complete information

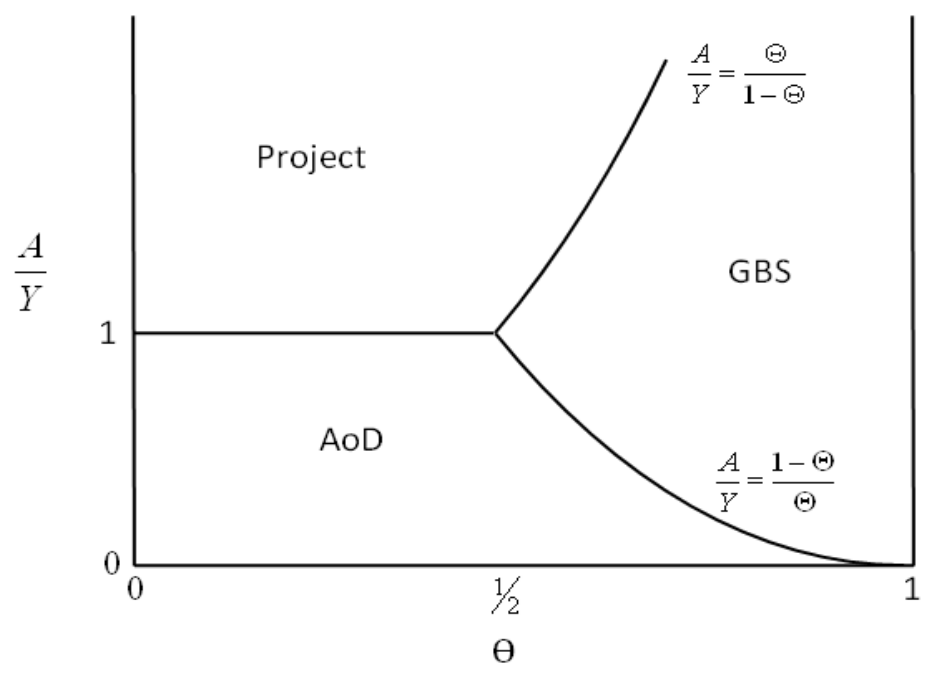

Source: Author's illustration

The comparison of allocations to ppe (i.e. donor utility) and government utility under the three different approaches given in Table 1 also shows that, not surprisingly, the preference ordering of modalities by the donor and the recipient government are incompatible over a large range of values for $\Theta$ and $\frac{A}{Y}$. Figure 11 shows the different preference orders in a commitment / aid dependency diagram. ${ }^{38}$

${ }^{38}$ Obviously, this ordering could change if the individual aid modalities were subject to different transaction costs. However, for the further analysis of this paper we shall abstract from transaction costs in order to examine the fundamental mechanism of aid allocation under different aid modalities. We will briefly come back to the issue of transaction costs in the conclusions. 
Figure 11: Preferred aid modalities with complete information

Donor

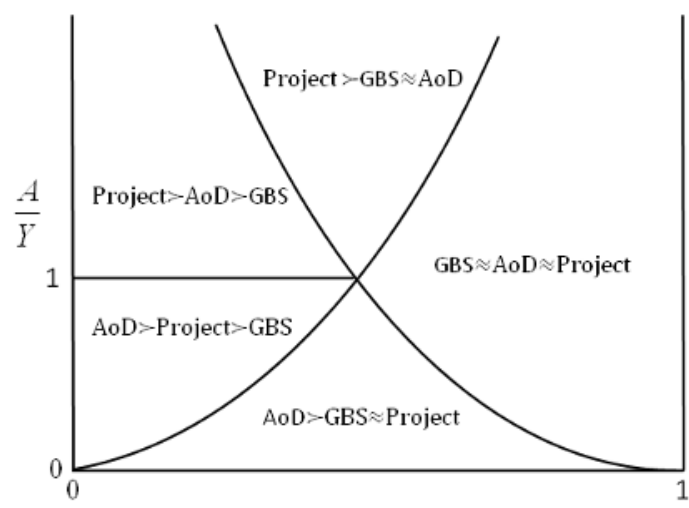

$\theta$
Government

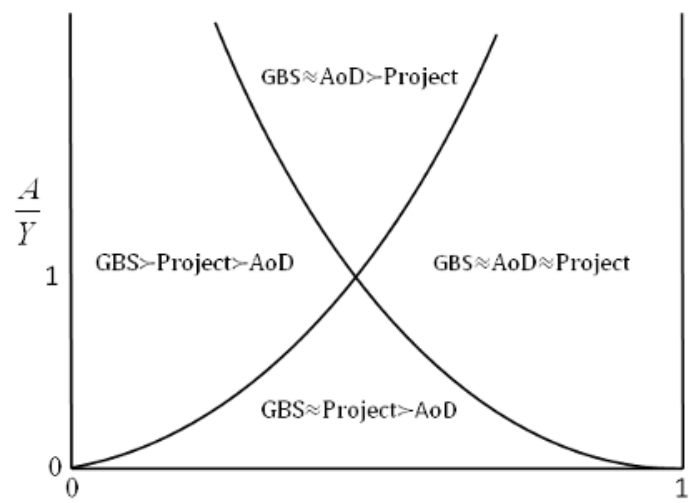

$\theta$

Source: Author's illustration

This matters, because the results of this analysis hinge on the assumption that both, the government and the donor, are perfectly informed about all relevant parameters, i.e. the government's own revenue $Y$, the aid budget $A$, and the government's commitment to poverty reduction $\Theta$. While for the first two parameters it seems justified to assume that in practice all actors involved would have at least roughly correct estimates of the true values, it can be expected that the donor has at best imperfect information on the government's commitment to poverty reduction.

The following sections examine the effects of asymmetric information on government commitment on the relative effectiveness of the different aid modalities.

\section{Asymmetric information and aid fungibility}

\subsection{The single donor case}

To analyze the impact of information asymmetries on the relative effectiveness of aid modalities let us again consider the three modalities project aid, unconditional, and performancebased budget support discussed in the previous sections. Assume a situation, where a donor gives project aid and is considering to offer the recipient government a switch to budget support in one of the two forms described in the previous section.

This situation is best framed as a two-stage decision process between the donor and the government: At the first stage, the government can choose between project aid and the option to receive budget support. It will choose the modality generating the highest utility given its endowment with $Y$, the available aid budget $A$, and its relative commitment to the two domestic interest groups $\Theta$. 
For comparability, assume that the aid budget $A$ remains the same for either aid modality but that opting for budget support means that the government has to grant donors insight into its budget plan. ${ }^{39}$

To reflect the information asymmetry between the donor and the government with respect to the latter's true commitment to poverty reduction, assume that the donor has no possibility to verify the government's true commitment ex-ante nor during budget implementation, e.g. by means of an analysis of the actual expenditure outturn. ${ }^{40}$

Furthermore, assume that in the case of performance-based budget support, however, the donor can and will demand proof of expenditure on ppe that is to be matched with an aid transfer. Importantly, this does not imply that the donor can derive the government's commitment, as the total total allocation to pro-poor expenditure from the domestic budget could be higher. The government only needs to provide proof for the amount ppe spending it wants to be matched with the corresponding aid transfer. ${ }^{41}$

The two domestic interest groups, in contrast, are assumed to be either perfectly informed about the government's true preferences (expressed by $\Theta$ ) or to be only interested in actual allocations and thus indifferent to the commitment claimed ex-ante by the government. ${ }^{42}$

Taken together, these assumptions mean that the government can deceive the donor about its true commitment to poverty reduction by rewriting its budget plan in case it opts for budget support at no domestic political cost. By doing so, the government can signal its commitment to poverty reduction to the donor by pretending to plan for an autarky allocation of $\widetilde{p p e}^{a}$ from which the donor will then derive her presumption on the government's

39 Note that in order to keep the analysis simple, we deliberately abstract from possible information and incentives generated by repeated interaction between donors and recipient governments, which evidently could reduce the information asymmetry. To an extent, this represents a 'worst case' benchmark case, in which budget support modalities are not given any informational advantage over project aid. We will briefly come back to the issue of repeated interaction in the final steps of the analysis.

${ }^{40}$ In practice, of course, donors do try to ensure an ex-post verification, either by demanding timely reports by an independent supreme audit institution (e.g. the auditor general) or by conducting own reviews such as public expenditure reviews, or expenditure tracking surveys. For an overview of diagnostic tools employed by donors for this purpose, see Allan et al. (2004) or Leiderer (2004).

${ }^{41}$ Note that this assumption is only necessary here because performance-based budget support is conditioned on government expenditure and not - as in practice - on observable outcome or performance indicators. Here, it is assumed that the donor cannot observe outcome indicators, which is necessary because of the assumption made earlier that the donor knows the technology by which public expenditure is transformed into poverty reduction - as this would allow the donor to deduce the total allocation to ppe from the observed outcomes. As the main aim of this section is to understand the effect of information asymmetries with respect to government commitment, this assumption thus merely serves to reintroduce this (arguably realistic) information asymmetry in the donor-recipient relation.

42 Given the limited transparency and credibility of budget plans in many developing countries (see, for example, IBP 2010: 3), this seems a fairly plausible assumption. It is common in aid dependent countries for donors to have significantly more information on budget issues than the general public and sometimes even the parliament (IBP 2010: 4, Resnick 2012: 9). There is also (anecdotic) evidence that domestic actors in many developing countries do not take the formal budget process seriously as an indication of the government's intentions with regard to public expenditure patterns (e.g. Rakner et al. 2004, Leiderer et al. 2007). 
commitment $\Theta$. Let this signal by the government be denoted as $\widetilde{\Theta} .^{43}$

Next, assume that the donor will base her aid modality choice on her knowledge of $A, Y$, and the 'signal' $\widetilde{\Theta}$. As the best allocation and thus utility the government can attain differs between modalities, this obviously might create an incentive for the government to lie about its true commitment to poverty reduction. Whether this is the case for the types of budget support discussed here and if so how this affects aid effectiveness shall be analyzed in the subsequent sections.

General budget support First, consider the case where the donor offers unconditional budget support, but can decide to stick to project-based aid if she finds the government's commitment to reduce poverty is insufficient. More specifically, let us assume that this is the case if the donor expects the government to spend less on pro-poor expenditure ppe than it receives in aid, because clearly in this case project aid yielding $p p e=A$ would be preferred by the donor. Following from the analysis above, this would be the case if $\widetilde{\Theta}(Y+A)<A$ or $\widetilde{\Theta}<\frac{A}{Y+A}$, which is the threshold above which project based aid is equivalent to unconditional budget support. Since for values at or above this threshold the donor is indifferent between the two modalities, let us assume that (for reasons unrelated to any of the parameters in this model) in this case she always chooses budget support.

Remember that under autarky the optimal allocation to ppe from the government's point of view is $\Theta Y$. Hence, if $\Theta \geq \frac{A}{Y+A}$ the government has no incentive to lie about its true preferences and will set $\widetilde{\Theta}=\Theta,{ }^{44}$ by budgeting $\widetilde{p p e}^{a}=\Theta Y$, and ${\widetilde{x_{0}}}^{a}=(1-\Theta) Y$. If, however, $\Theta<\frac{A}{Y+A}$, the government has an incentive to exaggerate its commitment to poverty reduction by budgeting $\widetilde{p p e}^{a} \geq \frac{A}{Y+A} \cdot Y$ and thereby signalling

$$
\widetilde{\Theta} \geq \frac{A}{Y+A}
$$

in order to avoid the donor choosing project aid instead of unconditional budget support.

However, because aid in the form of GBS is fully fungible, the government will then be able to choose its actual expenditure according to its true $\Theta$, i.e. ppe $=\Theta(Y+A)$, which in this case is smaller than the aid transfer $A$. Hence, if the donor has no way of establishing the government's true $\Theta$ ex ante, she will always end up providing GBS without being able to limit the extent of aid fungibility by switching to project aid in case of too low government commitment. In other words, by giving the government the option to receive unconditional budget support in a situation with asymmetric information (and basing her decision exclusively on the government's claimed commitment), the donor always ends up with ppe $=\Theta(Y+A)$, which in case $\Theta<\frac{A}{Y+A}$ is less than the aid budget $A$ and involves funding $x_{0}$ over and above the governments own resources $Y$ by the amount of $A-\Theta(Y+A)$.

43 As this 'signal' is effectively free for the government, i.e. there are no costs involved in giving a untruthful signal on its commitment, in strict economic terminology this kind of information would commonly be described as 'cheap talk' rather than an actual signal of the government's commitment.

${ }^{44}$ It is assumed here that the government will only lie about its commitment if it has an incentive to do so. 
Aid on delivery Next, consider a similar situation where at the first stage the government is given the choice between project aid and budget support, this time in the form of AoD type performance-based support. As can easily be seen from Figure 10, the donor should offer project aid for $1<\frac{A}{Y}>\frac{\widetilde{\Theta}}{1-\widetilde{\Theta}}$. For $1>\frac{A}{Y}<\frac{1-\widetilde{\Theta}}{\widetilde{\Theta}}$, she should prefer to provide AoD. It thus proves useful to distinguish between situations where $\frac{A}{Y} \leq 1$ and $\frac{A}{Y}>1$.

First, let us consider a situation where the donor's aid budget is not larger than the government's domestic budget, i.e. $\frac{A}{Y} \leq 1$.

To begin with, assume that the government's true commitment was $\Theta<\frac{Y}{Y+A}$ (i.e. $\frac{A}{Y}<\frac{1-\Theta}{\Theta}$ ). As the analysis in the previous section showed, for values of $\frac{A}{Y} \leq 1-\Theta$, the donor would then strictly prefer AoD to project aid and - under complete information - would set the matching element according to the rule given by (23) to adjust for the fungibility problem. Thus, for $\Theta \leq 1-\frac{A}{Y}$, if the government revealed its true $\Theta$, the best attainable allocation for it would be in $p p e=\Theta Y+A ; x_{0}=(1-\Theta) Y$.

In this point, the government's utility is strictly lower than with project aid, under which the best allocation is ppe $=A ; x_{0}=Y$ for $\Theta<\frac{A}{Y+A}$ and $p p e=\Theta(Y+A) ; x_{0}=(1-\Theta)(Y+A)$ for $\Theta \geq \frac{A}{Y+A}$ (see Table 1). In this case the government would thus be better off with sticking to project aid.

However, by understating its commitment to poverty reduction in the form

$$
\widetilde{\Theta}_{A o D}=\Theta-(1-\Theta) \frac{A}{Y}
$$

the government can induce the donor to set

$$
\varepsilon_{\widetilde{\Theta}}^{*}=\frac{A}{\widetilde{\Theta}_{A o D} Y+A}=\frac{A}{\Theta(Y+A)} .
$$

This ensures that the donor's matching aid is exhausted at point F in Figure 12 where the break of the government's effective budget constraint lies exactly at the intersection with $t_{\Theta}$. By doing so, the government is able to attain its preferred allocation $p p e^{*}=\Theta(Y+A)$ and $x_{0}^{*}=(1-\Theta)(Y+A)$.

Note that the right hand expression of (26) is smaller than $\Theta$ for all $0<\Theta<1$ and, thus, for $\frac{A}{Y} \leq 1$ and $\Theta \leq 1-\frac{A}{Y}$ the government will signal a lower than its true level of commitment to poverty reduction. Because the government is understating its true commitment, it will always be able to prove sufficient domestically financed expenditure on $p p e^{a}$ to be consistent with $\widetilde{\Theta} .{ }^{45}$

Importantly, because $\Theta-(1-\Theta) \frac{A}{Y}<1-\frac{A}{Y}$ for all $\Theta<\frac{Y}{Y+A}$, by choosing its signal $\widetilde{\Theta}$ according to (26), the government will also prevent the donor from reducing the matching element to $\varepsilon^{\prime \prime}=1-\widetilde{\Theta}$ (as it would for values of $1-\frac{A}{Y}<\widetilde{\Theta}<\frac{Y}{Y+A}$ ) in line with (24), thereby ensuring full disbursement of the aid budget $A$.

45 This means that even in this case, the 'signal' does not involve any cost for the government and is thus not a real signal in a strict economic sense. 
Figure 12: Aid on delivery with asymmetric information

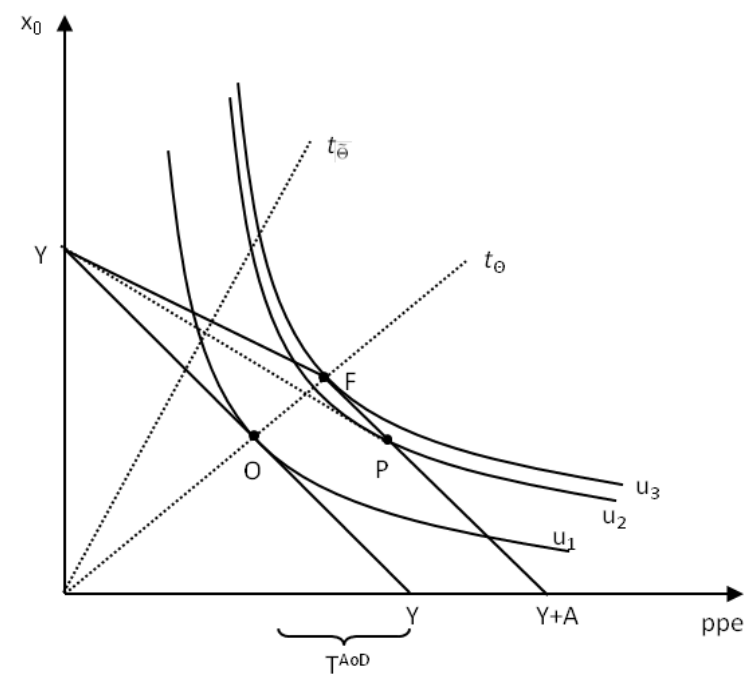

Source: Author's illustration

For $\Theta \geq \frac{Y}{Y+A}$, however, the government cannot understate its commitment in line with (26) and at the same time ensure that the donor sets $\varepsilon$ according to (27) as in this case the signal $\widetilde{\Theta}$ would still be larger than $1-\frac{A}{Y}$ and the donor would set $\varepsilon^{\prime \prime}$. In any case, for $\Theta \geq \frac{Y}{Y+A}$, the government does not need to misstate its commitment, since in this range for $\frac{A}{Y} \leq 1$, the donor and the government, are indifferent between all three aid modalities as all three yield $p p e^{*}=\Theta(Y+A)>A$.

Now let us turn to a situation where $\frac{A}{Y}>1$. With complete information, for any $\Theta<\frac{A}{Y+A}$, the donor would want to stick to project aid yielding $p p e^{*}=A$ rather than providing AoD, which would induce $p p e^{*}=Y<A$. The government, in turn, would want to stick to project aid only for $\Theta \leq \frac{Y}{Y+A} 46$ and prefer to switch to AoD for $\frac{Y}{Y+A}<\Theta<\frac{A}{Y+A}$. For $\Theta \geq \frac{A}{Y+A}$, both would be indifferent between the two aid modalities.

As it turns out, for $\frac{Y}{Y+A}<\Theta<\frac{A}{Y+A}$, the government can induce the donor to provide AoD instead of project aid, simply by overstating its commitment in the same way as in the case of unconditional budget support by choosing $\widetilde{\Theta}=\frac{A}{Y+A}$. Because for $\frac{A}{Y}>1$ the signal $\widetilde{\Theta}=\frac{A}{Y+A}$ is larger than $1-\frac{A}{Y}$, the donor sets her matching element to $\varepsilon^{\prime}=\frac{A}{Y}$ and the government can then allocate in its preferred $p p e^{*}=\Theta(Y+A) \cdot{ }^{47}$

For $\Theta<\frac{Y}{Y+A}$, however, overstating its commitment in the same way by signalling $\widetilde{\Theta}=\frac{A}{Y+A}$ comes at a cost for the government, because inducing the donor to stick to AoD but adjusting the matching element to $\varepsilon=\frac{A}{Y}$ means that the government has to provide proof of domestic expenditure to ppe $=Y$. Ensuring disbursement of the full aid budget $A$ thus implies that

${ }^{46}$ Assuming a donor agency that prioritizes efficiency over budget maximization.

47 As derived above, the donor in this case has no incentive to limit the matching element to a value lower than $\frac{A}{Y}$. Note that, again, it is not costly for the government to send this signal because its optimal allocation to $p p e^{*}=\Theta(Y+A)$ in this case is larger than $Y$, which means that it will always be able to provide proof for $p p e^{a}=Y$, which is consistent with $\widetilde{\Theta} \geq \frac{A}{Y+A}$ and ensures full disbursement of $A$. 
the government in this case cannot allocate in its preferred ppe $=\Theta(Y+A)$, which in this case is smaller than $Y .{ }^{48}$ Because the achievable allocation of $p p e^{*}=Y ; x_{0}^{*}=A$ in this case is still better from the government's perspective than the allocation $p p e^{*}=A ; x_{0}^{*}=Y$ possible under project aid, the government still has an incentive to overstate its commitment in this way.

Table 2 summarizes the effects of asymmetric information about the government's commitment on the attainable allocations to ppe (and thus donor utility). As the last column shows, if under asymmetric information the government can lie about its true commitment by writing up an unrealistic budget plan and the donor bases her decision on this plan, the donor will always end up with ppe $=\Theta(Y+A)$ if she offers the choice between project aid and GBS. The same is true over a large range of aid dependency / commitment combinations if she offers either project aid or AoD and only for an aid dependency ratio higher than 1 and government commitment $\Theta<\frac{Y}{Y+A}$ will she be able to achieve $p p e^{*}=Y>A$ with this aid modality. ${ }^{49}$

Table 2: Aid effectiveness with asymmetric information

\begin{tabular}{|c|c|c|c|c|c|}
\hline Modality choice & $\frac{A}{Y}$ & $\Theta$ & $\widetilde{\Theta}$ & $\widetilde{\Theta} \lesseqgtr \Theta$ & $p p e^{*}$ \\
\hline \multirow{2}{*}{ Project / GBS } & \multirow{2}{*}{$\forall$} & $\Theta<\frac{A}{Y+A}$ & $\frac{A}{Y+A}$ & $>$ & \multirow{2}{*}{$\Theta(Y+A)$} \\
\hline & & $\Theta \geq \frac{A}{Y+A}$ & $\Theta$ & $=$ & \\
\hline \multirow{3}{*}{ Project / AoD } & $\leq 1$ & $\begin{aligned} \Theta & <\frac{Y}{Y+A} \\
\Theta & \geq \frac{Y}{Y+A}\end{aligned}$ & $\begin{array}{c}\Theta-(1-\Theta) \frac{A}{Y} \\
\Theta\end{array}$ & $\begin{array}{l}< \\
=\end{array}$ & \multirow{2}{*}{$\Theta(Y+A)$} \\
\hline & \multirow[t]{2}{*}{$>1$} & $\begin{array}{c}\Theta \geq \frac{A}{Y+A} \\
\frac{Y}{Y+A} \leq \Theta<\frac{A}{Y+A}\end{array}$ & $\begin{array}{c}\Theta \\
\frac{A}{Y+A} \\
\end{array}$ & $\begin{array}{l}= \\
>\end{array}$ & \\
\hline & & $\Theta<\frac{Y}{Y+A}$ & $\frac{A}{Y+A}$ & $>$ & $Y$ \\
\hline
\end{tabular}

The government can then maximize its utility by allocating the available resources in ppe $=\Theta(Y+A) ; x_{0}=(1-\Theta)(Y+A)$, independent of the modality through which aid is provided. Importantly, however, the government does so by overstating its commitment to poverty reduction in the case of GBS for $\Theta<\frac{A}{Y+A}$ and by understating it in the case of AoD for $\Theta<\frac{Y}{Y+A}$. It is thus an interesting question whether donors could exploit these opposing incentives to reduce the information asymmetry and thus the problem of fungibility of its aid resources.

48 As established in the analysis without information asymmetries, it is still strictly better for the government to do so rather than expend less domestic resources and reduce the disbursed aid.

49 In the absence of differences in transaction costs between aid modalities, the donor could of course decide not to offer $\mathrm{AoD}$ for any aid dependency ratio larger than 1 as she is either indifferent or prefers project aid over AoD for all combinations of $\Theta$ and $\frac{A}{Y}$ in this range. In doing so, she could overcome the information asymmetry for this range of $\frac{A}{Y}$ at no cost. Of course there are other reasons why in the real world this would most likely not be a good solution, high transaction costs of projects being but one. 
The remainder of this paper examines the incentives for the government in case the two budget support modalities GBS and AoD are combined. This is done, first, by examining the case that two donors independently use the two different aid modalities, before moving on to the case of a co-ordinated modality mix.

\subsection{Unco-ordinated aid}

This section examines whether the unco-ordinated combination of unconditional budget support (GBS) and performance-based budget support (AoD) can help to mitigate the fungibility problem under asymmetric information.

For the case of unco-ordinated support, assume that instead of only one donor there are now two donors $\left(D_{1}\right.$ and $\left.D_{2}\right)$ willing to provide aid to a given developing country. Both donors independently give the government the choice between project-based aid and budget support, one in the form of GBS, the other in form of AoD. The condition set by both donors for the government to be eligible for these aid modalities is that it grants them insight into its national budget plan before they decide on how to disburse their aid.

Again, assume that the donors have no prior information on the government's true commitment $\Theta$ to reduce poverty and base their decision exclusively on the domestic allocation the government claims in its budget plan before receiving aid. As before, the donors are assumed to know the government's endowment with domestic resources $Y$ and the general shape of its utility function, which is assumed to be of the form given in Equation (3).

The government can thus send a signal on its commitment by budgeting $\widetilde{\Theta} Y$ of its own resources for pro-poor expenditure ppe and $(1-\widetilde{\Theta}) Y$ to alternative uses $x_{0}$. Again, assume that the government can choose this signal $\widetilde{\Theta}$ independent of its true $\Theta .{ }^{50}$ Based on $\widetilde{\Theta}$ the donors then decide on their disbursement. In order to analyze the case of unco-ordinated aid, assume the two donors do not know about each other's offer to provide aid and thus base their decision only on the signal $\widetilde{\Theta}$, their information on the government's domestic revenue $Y$ and their individual aid budgets $A_{1}$ and $A_{2}$.

Unlike both donors, the government knows the total available aid budget $A=A_{1}+A_{2}$ and thus, from the government's perspective, the two portions of the total aid budget can be denoted as $A_{1}=\alpha A$ and $A_{2}=(1-\alpha) A .^{51}$

Now assume that $D_{1}$ offers the government either GBS or project aid, $D_{2}$ offers either AoD with a matching element $\varepsilon$ or project aid. Both base their decisions on the same considerations as in the analysis above, but ignore each other's aid provision.

${ }^{50}$ Remember that this assumes that the 'signal' bears no political cost for the government as the two interest groups (the poor and the rich) are only interested in actual allocations and not in the budget plan. Again, this could be either because the budget is only made transparent to the donors and not to the public (in particular the poor) or because they know that it is merely a signaling tool aimed at the donors (probably more likely in case of the rich elite). Nonetheless, because the signal is documented in the government's budget plan, it is not possible for the government to send different signals to the individual donors.

51 As we are interested in the multi-donor case here, we assume positive aid budgets for both donors and thus $0<\alpha<1$. 
As established in the single donor case, $D_{1}$ - considering only her individual aid budget $\alpha A$ has an incentive to switch to project aid for all $\widetilde{\Theta}<\frac{\alpha A}{Y+\alpha A}$. In turn, for $D_{2}$ there is only an incentive to switch to project aid for $\frac{\widetilde{\Theta}}{1-\widetilde{\Theta}}<\frac{(1-\alpha) A}{Y}>1$.

Even though each donor considers only her individual aid budget $A_{i}$, it proves helpful to distinguish between situations where overall aid dependency $\frac{A}{Y}$ is greater than 1 and where it is not.

Let us therefore first analyse the case that $\frac{A}{Y} \leq 1$, which implies that $\frac{(1-\alpha) A}{Y}<1$, for which $D_{2}$ never switches to project aid. From the government's perspective, the donors' disbursement schedules then take the following form: $D_{1}$ will provide GBS for $\widetilde{\Theta} \geq \frac{\alpha A}{Y+\alpha A}$ and project support of $\alpha A$ otherwise. $D_{2}$ always offers AoD, but adjusts the matching element as

- $\varepsilon^{*}=\frac{(1-\alpha) A}{\widetilde{\Theta} Y+(1-\alpha) A}$ for $\widetilde{\Theta} \leq 1-\frac{(1-\alpha) A}{Y}$;

- $\varepsilon^{\prime \prime}=1-\widetilde{\Theta}$ for $1-\frac{(1-\alpha) A}{Y}<\widetilde{\Theta}<\frac{Y}{Y+(1-\alpha) A}$; and

- $\varepsilon^{\prime}=\frac{(1-\alpha) A}{Y}$ for $\widetilde{\Theta} \geq \frac{Y}{Y+(1-\alpha) A}$.

In this setting, the government's budget constraint will have a the double-kinked shape similar to the one depicted on the left hand side in Figure 13 in case $D_{1}$ chooses to provide project aid. If $D_{1}$ chooses GBS, the combined budget constraint will have shape depicted in the the right hand side graph in Figure 13.

Figure 13: Budget constraints with unco-ordinated aid

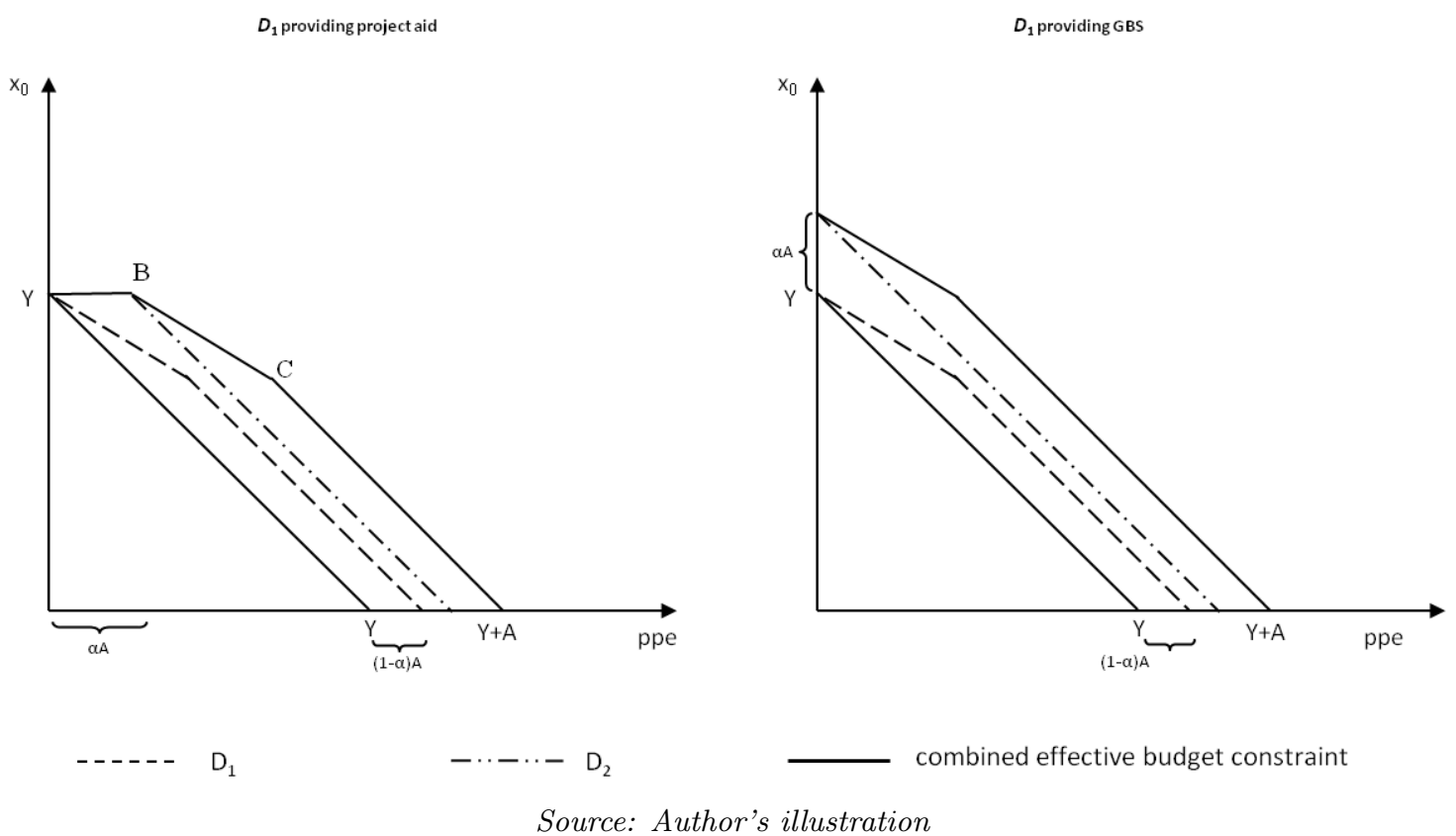

To begin with, assume the government's true $\Theta$ is smaller than $D_{1}$ 's threshold of $\frac{\alpha A}{Y+\alpha A}$. $D_{1}$ would then want to provide project aid and thus, if the government chooses to signal its true commitment by setting $\widetilde{\Theta}=\Theta$, it will face a double-kinked budget constraint as in the 
left hand side of Figure 13. From the previous analysis, it can be deduced that in this case the best allocation for the government must be either on one of the two budget constraint breaks $B$ or $C$, or somewhere between these two points, i.e. $\alpha A \leq p p e^{*} \leq \Theta Y+(1-\alpha) A$.

In any case, in this situation the government could always increase its utility by stating a lower $\widetilde{\Theta}$ in order to induce $D_{2}$ first to set (in case $\Theta>1-\frac{(1-\alpha) A}{Y}$ ) and then increase $\varepsilon_{\widetilde{\Theta}}^{*}=\frac{(1-\alpha) A}{\widetilde{\Theta} Y+(1-\alpha) A}$ and move the second breaking point $C$ further up.

Because this holds for all $\frac{\alpha A}{Y+\alpha A}>\widetilde{\Theta}>0$, the government would have an incentive to state an infinitesimal small $\widetilde{\Theta}$, for which $\varepsilon^{*} \rightarrow 1$ and AoD becomes asymptotically equivalent to project aid. The best allocation for the government then moves asymptotically towards ppe $=A, x_{0}=Y$. This case is illustrated in the left diagram of 14, where the government is best off by allocating in the corner solution $L$ and moving this point upwards by reducing $\widetilde{\Theta}$.

Figure 14: Unco-ordinated aid with low government commitment

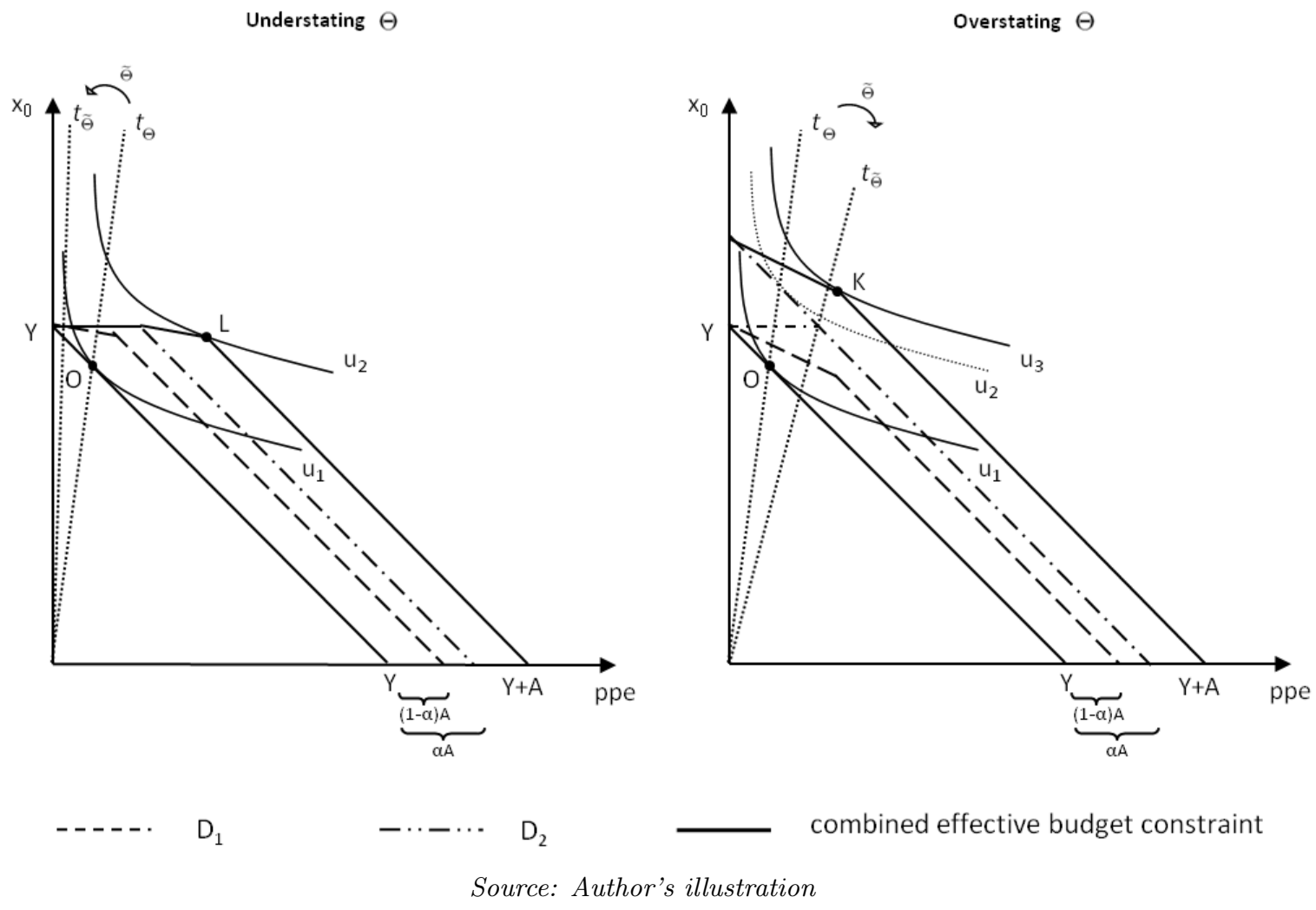

From the government's perspective this allocation is marginally inferior to receiving the entire aid budget as project aid, from the donor's perspective it is marginally superior.

On the other hand, if the government would overstate its commitment by setting $\widetilde{\Theta}=\frac{\alpha A}{Y+\alpha A}$ so that $D_{1}$ is just indifferent between GBS and project aid (and thus presumably will provide budget support), it faces a budget constraint as in the left hand graph of Figure 13. 
Because $\frac{\alpha A}{Y+\alpha A}$ is always smaller than $1-\frac{(1-\alpha) A}{Y}\left(D_{2}\right.$ 's lower threshold to adjust $\left.\varepsilon\right)$ for $\frac{A}{Y}<1$ and $0<\alpha<1, D_{2}$ will set the matching element $\varepsilon^{*}$, which in this case takes the form

$$
\varepsilon_{\widetilde{\Theta}}^{*}=\frac{(1-\alpha) A}{\widetilde{\Theta} Y+(1-\alpha) A}=1-\frac{1}{(1-\alpha) \frac{A}{Y}+\frac{1}{\alpha}}
$$

Whether the government is able to reach its preferred allocation of $p p e^{*}=\Theta(Y+A)$ or is best off allocating in the corner solution indicated by point $K$ in the right hand graph of Figure 14, depends on where the line $t_{\Theta}{ }^{52}$ intersects with the effective budget constraint generated by $D_{1}$ providing GBS and $D_{2}$ setting $\varepsilon_{\widetilde{\Theta}}^{*} \cdot{ }^{53}$

Since with $\varepsilon^{*}$ set according to (28) the government's effective budget constraint breaks at ppe $=\widetilde{\Theta} Y+(1-\alpha) A=A\left(1-\frac{\alpha^{2} A}{Y+\alpha A}\right)$, the allocation to ppe yielded for $\Theta<\frac{\alpha A}{Y+\alpha A}$ is given by

$$
p p e^{*}= \begin{cases}A\left(1-\frac{\alpha^{2} A}{Y+\alpha A}\right) & \forall \quad \frac{\alpha A}{Y+\alpha A}>\Theta<\frac{A}{Y+A}\left(1-\frac{\alpha^{2} A}{Y+\alpha A}\right) \\ \Theta(Y+A) & \forall \quad \frac{\alpha A}{Y+\alpha A}>\Theta \geq \frac{A}{Y+A}\left(1-\frac{\alpha^{2} A}{Y+\alpha A}\right)\end{cases}
$$

Because the corner solution $K$ in the right hand graph in Figure 14 is strictly preferred to the corner solution $L$ in the left hand situation, for $\Theta<\frac{\alpha A}{Y+\alpha A}$ the government is always better off by overstating its commitment $\Theta$ according to $\widetilde{\Theta}=\frac{\alpha A}{Y+\alpha A}$ than by understating it. At the same time, as established in the single donor case, the government clearly has no incentive to overstate $\widetilde{\Theta}$ above this value, as this would reduce $\varepsilon^{*}{ }^{54}$

In turn, for $\frac{A}{Y+A}\left(1-\frac{\alpha^{2} A}{Y+\alpha A}\right) \leq \Theta=\frac{\alpha A}{Y+\alpha A}$, the government would have no incentive to lie about its commitment and would thus state $\widetilde{\Theta}=\Theta$. From these results it also follows that the government has no incentive to choose project-based aid from donor $D_{1}$ instead of budget support. Hence, for all $\Theta \leq \frac{\alpha A}{Y+\alpha A}$ the government will set $\widetilde{\Theta}=\frac{\alpha A}{Y+\alpha A}$.

Next, consider the case that government commitment $\Theta>\frac{\alpha A}{Y+\alpha A}$. Clearly, for any $\Theta \geq \frac{Y}{Y+(1-\alpha) A}$, the government has no incentive to misstate its commitment since signalling $\widetilde{\Theta}=\Theta$ will induce $D_{1}$ to provide $\mathrm{GBS}^{55}$ and $D_{2}$ to set the matching element as $\varepsilon^{\prime}=\frac{(1-\alpha) A}{Y}$. This always allows the government to allocate in its preferred $\Theta(Y+A)$, as illustrated in the left hand graph of Figure 15.

${ }^{52}$ Remember that $t_{\Theta}$ represents the loci where the government's indifference curves have the same slope as the autarky budget constraint, i.e. -1 .

${ }^{53}$ Note that, in order to signal $\widetilde{\Theta}=\frac{\alpha A}{Y+\alpha A}$, and to ensure that the entire performance-based budget support $(1-\alpha) A$ will be disbursed, the government has to prove expenditure to $D_{2}$ of at least $A\left(1-\frac{\alpha^{2} A}{Y+\alpha A}\right)$, which is where the effective budget constraint breaks. As $D_{1}$ 's contribution of $\alpha A$ moves this break upwards, the government is not able to choose a tangent solution on the flat segment of the budget constraint with the full aid budget disbursed. At the same time, the government is always better off ensuring that the full aid budget is disbursed and $D_{1}$ provides GBS than when choosing a smaller $\widetilde{\Theta}$

${ }^{54}$ Although for $1-\frac{\alpha A}{Y} \geq \widetilde{\Theta} \geq(\Theta-1-\alpha)$ the government could still allocate in $\Theta(Y+A)$.

55 As for $\frac{A}{Y}<1, \frac{\alpha A}{Y+\alpha A}<\frac{Y}{Y+(1-\alpha) A}$ for all $0<\alpha<1$. 
Figure 15: Unco-ordinated aid with moderate to high government commitment
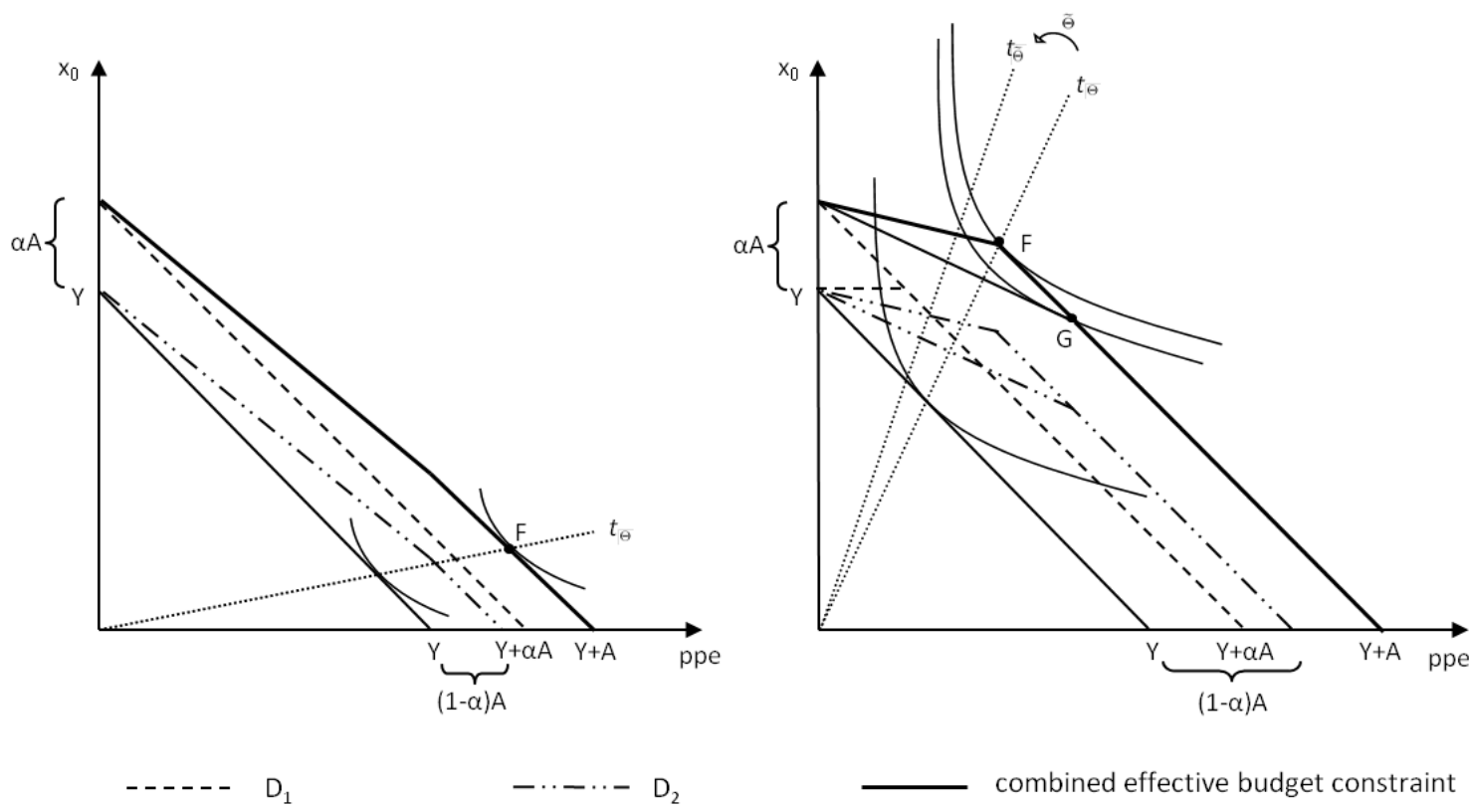

Source: Author's illustration

For values $\frac{Y}{Y+(1-\alpha) A}>\Theta>1-\frac{(1-\alpha) A}{Y}$ signalling $\widetilde{\Theta}=\Theta$ would induce $D_{2}$ to adjust her matching element to $\varepsilon^{\prime \prime}=1-\Theta$ and reduce her aid budget to $A^{\prime}=(1-\widetilde{\Theta}) Y<(1-\alpha) A .^{56}$ This is obviously not in the government's interest and it can avoid this by understating its commitment as $\widetilde{\Theta}=1-\frac{(1-\alpha) A}{Y}$, for which $D_{2}$ chooses $\varepsilon^{*}=\frac{(1-\alpha) A}{\widetilde{\Theta} Y+(1-\alpha) A}=\frac{(1-\alpha) A}{Y}$.

Yet, doing so would ensure full disbursement of $A_{2}$ only for $p p e^{a}=Y$, which would allow the government to allocate in its preferred $\Theta(Y+A)$ only for true $\Theta \geq \frac{Y}{Y+A}$ and in the corner solution in ppe $=Y ; x_{0}=A$ otherwise. However, by further reducing the signal to $\widetilde{\Theta}=\Theta-(1-\Theta-\alpha) \frac{A}{Y}$, the government can increase the matching element even more and ensure an allocation in $p p e^{*}=\Theta(Y+A)$ even for $\Theta<\frac{Y}{Y+A} .{ }^{57}$

Evidently, understating its commitment in this way then would also be the government's best choice for $\frac{\alpha A}{Y+\alpha A}<\Theta<1-\frac{(1-\alpha) A}{Y}$. This situation is illustrated in the right hand graph of Figure 15, where point $G$ is the best allocation possible if the government stated its true $\Theta$, and $F$ the allocation attainable by stating $\widetilde{\Theta}=\Theta-(1-\Theta-\alpha) \frac{A}{Y}$. However, the government can only do so, as long as $\Theta-(1-\Theta-\alpha) \frac{A}{Y} \geq \frac{\alpha A}{Y+\alpha A}$, or $\Theta \geq \frac{A}{Y+A}\left(1-\frac{\alpha^{2} A}{Y+\alpha A}\right),{ }^{58}$ as for lower values $D_{1}$ would switch to project aid. Because this is never preferred by the government, its best option for lower values of $\Theta$ is then to state $\widetilde{\Theta}=\frac{\alpha A}{Y+\alpha A}$ and allocate in the corner solution. Because for $\frac{A}{Y}<1$ it is always true that $\frac{\alpha A}{Y+\alpha A}<1-\frac{(1-\alpha) A}{Y}, \mathrm{D}_{2}$ will in this case always set $\varepsilon^{*}=\frac{(1-\alpha) A}{\tilde{\Theta} Y+(1-\alpha) A}$ and the corner solution is given by $p p e^{*}=A-\frac{\alpha^{2} A 2}{Y+\alpha A}$; $x_{0}=Y+\frac{\alpha^{2} A^{2}}{Y+\alpha A}$.

56 Again, presuming that the donor agency prioritizes efficiency over budget maximization

57 Note that - while the outcome is the same - compared to the single donor case, the government needs to understate its commitment by a smaller margin because of the additional upwards shift of the budget constraint through $D_{1}$ 's contribution of $\alpha A$.

58 Note that the threshold is the same as the one that allows the government to allocate in $\Theta(Y+A)$ for values $\Theta \leq \frac{\alpha A}{Y+\alpha A}$. 
Table 3 summarizes the results of the analysis for unco-ordinated aid for $\frac{A}{Y} \leq 1$. As the attainable allocations to $p p e^{*}$ show, with two unco-ordinated donors providing aid, the fungibility problem of both budget support modalities persists over a wide range of combinations of low to moderate aid dependency and government commitment. But the unco-ordinated combination of GBS and AoD effectively establishes a lower limit for $p p e^{*}=A\left(1-\frac{\alpha^{2} A}{Y+\alpha A}\right)$. This lower limit is smaller than the lower limit for project aid ppe $=A$, which means that in the absence of transaction costs, donors should prefer to give project aid. It is, however, strictly larger than $(1-\alpha) A$, meaning that even the unco-ordinated combination of AoD with GBS increases the lower ppe limit for AoD.

Table 3: Effectiveness of unco-ordinated modality mix for $\frac{A}{Y} \leq 1$

\begin{tabular}{|c|c|c|c|c|}
\hline \multicolumn{3}{|c|}{$\Theta$} & $\widetilde{\Theta}$ & $p p e^{*}$ \\
\hline \multirow[b]{2}{*}{$\Theta<\frac{Y}{Y+(1-\alpha) A}$} & \multicolumn{2}{|c|}{$\Theta<\frac{A}{Y+A}\left(1-\frac{\alpha^{2} A}{Y+\alpha A}\right)$} & $\frac{\alpha A}{Y+\alpha A}$ & $A\left(1-\frac{\alpha^{2} A}{Y+\alpha A}\right)$ \\
\hline & $\Theta \geq \frac{A}{Y+A}\left(1-\frac{\alpha^{2} A}{Y+\alpha A}\right)$ & $\begin{array}{l}\Theta \leq \frac{\alpha A}{Y+\alpha A} \\
\Theta>\frac{\alpha A}{Y+\alpha A}\end{array}$ & $\begin{array}{c}\frac{\alpha A}{Y+\alpha A} \\
\Theta-(1-\Theta-\alpha) \frac{A}{Y}\end{array}$ & $\Theta(Y+A)$ \\
\hline \multicolumn{3}{|c|}{$\Theta \geq \frac{Y}{Y+(1-\alpha) A}$} & $\Theta$ & $\Theta(Y+A)$ \\
\hline
\end{tabular}

Let us now examine the case of high aid dependency, where $\frac{A}{Y}>1$. To begin with, assume that $D_{2}$ 's aid budget alone exceeds domestic revenue, i.e. $\frac{(1-\alpha) A}{Y}>1$. In this case, $D_{2}$ will switch to project aid for any $\widetilde{\Theta}<\frac{(1-\alpha) A}{Y+(1-\alpha) A}$. For $\widetilde{\Theta} \geq \frac{(1-\alpha) A}{Y+(1-\alpha) A}$, she will offer AoD with a matching element $\varepsilon^{\prime}=\frac{(1-\alpha) A}{Y}$.

For any $\frac{\alpha A}{Y+\alpha A} \leq \Theta \geq \frac{(1-\alpha) A}{Y+(1-\alpha) A}$ the government then has no incentive to misstate its commitment because $\widetilde{\Theta}=\Theta$ induces the donors to provide GBS and AoD, respectively, and enables the government to allocate in $p p e^{*}=\Theta(Y+A)$. For any $\Theta<\max \left(\frac{\alpha A}{Y+\alpha A}, \frac{(1-\alpha) A}{Y+(1-\alpha) A}\right)$ the government has an incentive to overstate its commitment as $\widetilde{\Theta}=\max \left(\frac{\alpha A}{Y+\alpha A}, \frac{(1-\alpha) A}{Y+(1-\alpha) A}\right)$ in order to prevent both donors from switching to project aid. For true $\Theta>\frac{Y}{Y+A}$, it will then be able to allocate in $p p e^{*}=\Theta(Y+A)$, and $p p e^{*}=Y ; x_{0}=A$ otherwise.

Figure 16 shows this latter case, where true $\Theta$ is larger than $\frac{\alpha A}{Y+\alpha A}$ (which means that $t_{\Theta}$ intersects with the budget constraint associated with $D_{1}$ 's GBS to the right of point $K$ ), but smaller than $\frac{(1-\alpha) A}{Y+(1-\alpha) A}$ (which means that $t_{\Theta}$ intersects with $D_{2}$ 's AoD budget constraint to the left of point $P$ ). The government thus signals $\widetilde{\Theta}=\frac{(1-\alpha) A}{Y+(1-\alpha) A}$ and allocates in point $F$.

Next, let us turn to the case that $\frac{A}{Y}>1$, but $\frac{(1-\alpha) A}{Y} \leq 1$, which implies that $D_{2}$ never switches to project aid. In principle the same mechanics are at work in this situation as in the case for $\frac{A}{Y} \leq 1$, with the exception that now it is possible that $\frac{\alpha A}{Y+\alpha A}>1-\frac{(1-\alpha) A}{Y}$, meaning that stating $\widetilde{\Theta}=\frac{\alpha A}{Y+\alpha A}\left(D_{1}\right.$ 's threshold) does not guarantee that $D_{2}$ will set the matching AoD element $\varepsilon$ according to (28). Therefore, as long as $\frac{\alpha A}{Y+\alpha A} \leq 1-\frac{(1-\alpha) A}{Y}$, the situation does not differ from $\frac{A}{Y} \leq 1$, resulting in allocation $p p e^{*}=A\left(1-\frac{\alpha^{2} A}{Y+\alpha A}\right)$ or $p p e^{*}=\Theta(Y+A)$, depending on the values for $\Theta$. 
Figure 16: Unco-ordinated aid with high aid dependencv

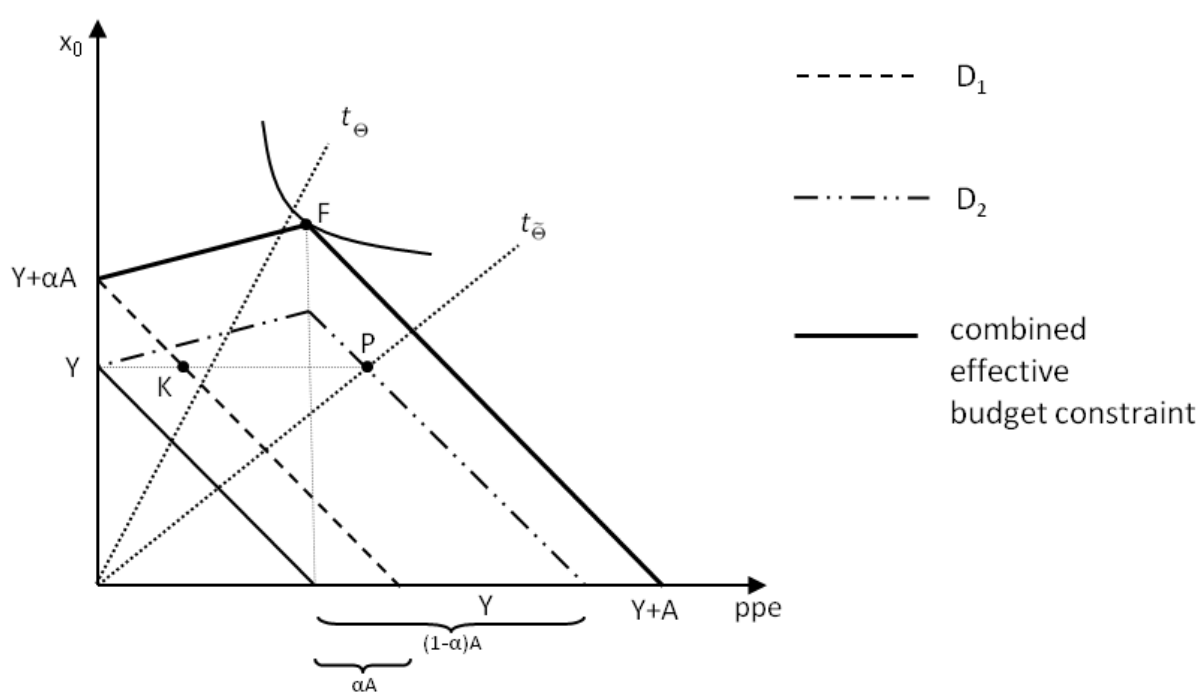

Source: Author's illustration

Now consider the case that $\frac{\alpha A}{Y+\alpha A} \geq \frac{Y}{Y+(1-\alpha) A}$. If government commitment $\Theta \geq \frac{\alpha A}{Y+\alpha A}$, then there will be no incentive to misstate $\Theta$ and the government will be able to allocate in $p p e^{*}=\Theta(Y+A)$. If $\Theta<\frac{\alpha A}{Y+\alpha A}$, the government could either understate its commitment, whereby - as before - the incentive would be to state an infinitesimal small $\widetilde{\Theta}$, induce $\varepsilon^{*} \rightarrow 1$ and allocate (asymptotically) in ppe $=A$; or it could overstate its commitment by signalling $\widetilde{\Theta}=\frac{\alpha A}{Y+\alpha A}$, at the cost of having to prove $p p e^{a}=Y$ to $D_{2}$ in order to induce full disbursement of $A_{2}$. As before, the latter would always be the preferred option for the government, allowing it to allocate in $p p e^{*}=\Theta(Y+A)$ for $\Theta \geq \frac{Y}{Y+A}$ and in $p p e^{*}=Y$ otherwise.

Finally, assume that $1-\frac{(1-\alpha) A}{Y}<\frac{\alpha A}{Y+\alpha A}<\frac{Y}{Y+(1-\alpha) A}$. For $\Theta<\frac{\alpha A}{Y+\alpha A}$ the government has two options: as before, by understating its commitment, the best it can achieve is to allocate (asymptotically) in ppe $=A$. If the government decides to overstate its commitment as $\widetilde{\Theta} \geq \frac{\alpha A}{Y+\alpha A}$ in order to prevent $D_{1}$ from switching to project aid, it is clearly sub-optimal to signal any $\widetilde{\Theta}<\frac{Y}{Y+(1-\alpha) A}$, since this would induce $D_{2}$ to offer $\varepsilon^{\prime \prime}=1-\widetilde{\Theta}$ and reduce $A_{2}$ to $A_{2}^{\prime}=(1-\widetilde{\Theta}) Y$. By signalling $\widetilde{\Theta} \geq \frac{Y}{Y+(1-\alpha) A}$ the government can induce $D_{2}$ to set $\varepsilon^{\prime}=\frac{(1-\alpha) A}{Y}$ and achieve the same allocation as in the previous situation, i.e. $p p e^{*}=\Theta(Y+A)$ for $\Theta \geq \frac{Y}{Y+A}$, and $p p e^{*}=Y$ otherwise, which - again - it would prefer. The same logic (and resulting signal and achievable allocations) applies for $\Theta \geq \frac{\alpha A}{Y+\alpha A}$.

Table 4 summarizes the results for unco-ordinated aid for $\frac{A}{Y}>1$. These results show that, while the general fungibility problem also applies in situations of high aid dependency, the effective lower limit for allocations to $p p e^{*}$ becomes $Y$ for values of $\frac{(1-\alpha) A}{Y}>\frac{Y}{Y+\alpha A}$ or $\frac{A_{2}}{Y}>\frac{Y}{Y+A_{1}}$. Again, this lower limit for pro-poor expenditure is smaller than $A$ and thus lower than the lower limit for project aid. 
Table 4: Effectiveness of unco-ordinated modality mix for $\frac{A}{Y}>1$

\begin{tabular}{|c|c|c|c|c|}
\hline$\frac{(1-\alpha) A}{Y}$ & $\Theta$ & $\widetilde{\Theta}$ & $\widetilde{\Theta} \Theta$ & $p p e^{*}$ \\
\hline $1<\frac{(1-\alpha) A}{Y}$ & $\Theta \geq \frac{Y}{Y+A}$ & $\max \left(\frac{\alpha A}{Y+\alpha A} ; \frac{(1-\alpha) A}{Y+(1-\alpha) A}\right)^{\star}$ & $\geq$ & $\Theta(Y+A)$ \\
$Y<\frac{Y}{Y+A}$ & & \\
\hline$\frac{Y}{Y+\alpha A}<\frac{(1-\alpha) A}{Y} \leq 1$ & $\begin{array}{c}\Theta \geq \frac{Y}{Y+A} \\
\Theta<\frac{Y}{Y+A}\end{array}$ & $\max \left(\frac{\alpha A}{Y+\alpha A} ; \frac{Y}{Y+(1-\alpha) A}\right)^{\star}$ & $\geq$ & $\Theta(Y+A)$ \\
\hline$\frac{(1-\alpha) A}{Y} \leq \frac{Y}{Y+\alpha A}$ & \multicolumn{5}{|l|}{ see Table 3 } \\
\hline${ }^{\star}$ For $\Theta>\max (\cdot ; \cdot)$, the government can also set $\widetilde{\Theta}=\Theta$ \\
\hline
\end{tabular}

Taken together, the results displayed in Tables 3 and 4 show that with two unco-ordinated donors providing different forms of budget support (GBS and AoD), the fungibility problem of both aid modalities persists over a wide range of combinations of aid dependency and government commitment. In the absence of transaction costs, donors should prefer to provide project aid, which ensures a higher lower bound for pro-poor expenditure $p p e=A$.

However, the fact that the individual donor's thresholds as well as the lower bound $A\left(1-\frac{\alpha^{2} A}{Y+\alpha A}\right)$ depend on the size and relative shares of the two donors' aid budgets, suggest that by coordinating their modality mix, donors could possibly compensate for the fungibility of aid resources even more effectively. The final step of the analysis examines this possibility.

\subsection{Donor co-ordination and aid effectiveness}

'A key challenge for donors individually and collectively is to choose and design appropriate and complementary aid instruments so as to maximize their combined effectiveness' OECD-DAC (2006:19).

The previous section showed that by choosing different aid modalities, even if acting independently, donors can eliminate part of the fungibility problem arising from asymmetric information on the government's commitment to poverty reduction. It is thus a straightforward question whether, by coordinating a mix of GBS and AoD, donors can extend the disciplining effect of each form of budget support to the entire aid budget and thus further reduce the problem of aid fungibility.

Therefore, assume a situation similar to the one analyzed in the previous section, but with the difference that the two donors coordinate their aid. In principle, in the setting of the simple model presented here, donors have three coordination mechanisms at hand: (i) they can negotiate the share of the overall aid budget allocated to each modality; (ii) in the case of AoD, they can adjust the matching element; and (iii) they can agree on thresholds for (signalled) government commitment below which they re-program part of or their entire aid budget into project aid instead of budget support. 
An alternative way to think about this setting is as one in which a single donor (group) decides to disburse part of her (its) aid as a fixed GBS tranche and part as a variable performance-based AoD tranche. ${ }^{59}$ For the sake of simplicity, let us thus assume for the following analysis a similar setting as in the previous section but instead of two donors, there is only one donor (group ${ }^{60}$ with an aid budget $A$. This donor gives the recipient government the choice between project aid or budget support that is disbursed in form of a fixed tranche $\alpha A$ and a performance-based (or $\mathrm{AoD}$ ) tranche $(1-\alpha) A$.

This situation differs in two important aspects from the one described in the previous section: First, the donor now knows the total available aid budget $A$ and will thus adjust the matching element $\varepsilon_{\widetilde{\Theta}}$ for the performance tranche according to the overall budget, unlike in the case without donor coordination, where each donor considered only her individual aid budget. Second, the donor can take the entire aid budget into account in the formulation of a lower threshold for government commitment below which she decides to switch to project aid. In addition, she can decide to either re-program only the fixed tranche or the entire aid budget to project aid. ${ }^{61}$

The first point means that the donor would - following the same arguments as in the previously analyzed cases, but taking into account the fixed tranche $\alpha A$ - set the matching element according to the government's signal $\widetilde{\Theta}$ as:

- $\varepsilon^{*}=\frac{(1-\alpha) A}{\widetilde{\Theta}(Y+\alpha A)+(1-\alpha) A}$ for $\widetilde{\Theta} \leq 1-\frac{(1-\alpha) A}{Y+\alpha A}$;

- $\varepsilon^{\prime \prime}=1-\widetilde{\Theta}$ for $1-\frac{(1-\alpha) A}{Y+\alpha A}<\widetilde{\Theta}<\frac{Y+\alpha A}{Y+A}$; and

- $\varepsilon^{\prime}=\frac{(1-\alpha) A}{Y+\alpha A}$ for $\widetilde{\Theta} \geq \frac{Y+\alpha A}{Y+A}$.

The second point means that the donor has essentially three options: (1) she can always offer budget support in form of a fixed and a variable tranche; (2) she can establish a lower threshold for government commitment below which she reprograms the entire aid budget to project aid; or (3) she can formulate a threshold below which only the fixed GBS tranche is reprogrammed to project aid.

(1) First, assume the donor formulates no threshold at all and always disburses her aid as a combination of a fixed GBS and a variable AoD tranche. She does, however, decide on the parameter $\alpha$, i.e. the respective share of her aid budget allocates to each of the two tranches (or modalities). Analogously to the case of unco-ordinated aid, the government would then have no incentive to misstate its commitment to poverty reduction for $\Theta \geq \frac{Y+\alpha A}{Y+A}$ and would thus set $\widetilde{\Theta}=\Theta$, for which the donor would set the matching element as $\varepsilon^{\prime}=\frac{(1-\alpha) A}{Y+\alpha A}$ and the government could allocate in $\Theta(Y+A)$.

59 As a matter of fact, a number of donors do take this approach in practice, most prominently the European Commission (cf. Schmidt 2006).

${ }^{60}$ In the interest of readability, we also refer to a co-ordinated donor group as an individual donor in the remaining sections.

${ }^{61}$ From the analysis in the previous sections it is evident that it would not make sense for the donor to reprogramme only the AoD tranche. 
For $\frac{A}{Y} \leq 1$, and $\frac{(1-\alpha) A}{Y+A}<\Theta<\frac{Y+\alpha A}{Y+A}$, the government would have an incentive to understate its commitment as in the previous cases, but taking into account the adjusted matching element $\varepsilon^{*},{ }^{62}$ thus signalling

$$
\widetilde{\Theta}^{*}=\Theta-\frac{(1-\Theta)(1-\alpha) A}{Y+\alpha A}=1-(1-\Theta) \frac{Y+A}{Y+\alpha A}
$$

Again, for these values, the government can allocate in $p p e^{*}=\Theta(Y+A)$. For $\Theta<\frac{A}{Y+A}$ this implies that the donor will end up financing $x_{0}$ in excess of autarky income $Y$. This case is depicted in Figure 17.

Figure 17: Coordinated budget support without threshold

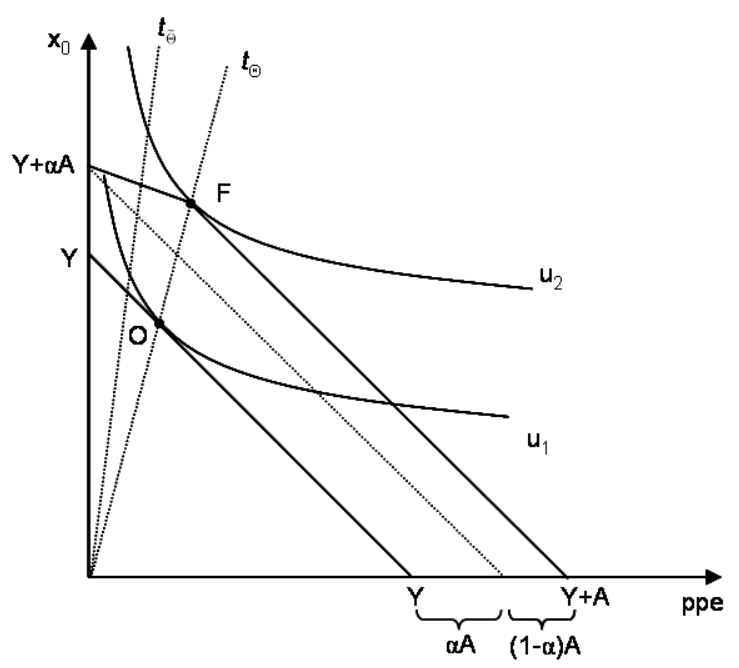

Source: Author's illustration

For $\Theta \leq \frac{(1-\alpha) A}{Y+A}$, however, the government cannot understate its commitment in line with (30) as this would imply $\widetilde{\Theta} \leq 0 .{ }^{63}$ Nonetheless, the government would still have an incentive to understate its commitment as much as possible as this moves point $F$ in Figure 17 upwards. It would thus state an infinitesimal small $\widetilde{\Theta}$ for which the allocation will then move asymptotically towards ppe $=(1-\alpha) A$ and $x_{0}=Y+\alpha A$, which would be equivalent to giving $\alpha A$ as GBS and $(1-\alpha) A$ as project aid.

For $\frac{A}{Y} \leq 1$, the resulting allocation to pro-poor expenditure with this approach would thus be $p p e^{*}=\Theta(Y+A)$ for all $\Theta>\frac{(1-\alpha) A}{Y+A}$ and asymptotically $p p e^{*}=(1-\alpha) A, x_{0}=Y+\alpha A$ for $\Theta \leq \frac{(1-\alpha) A}{Y+A}$

Evidently, it would then be in the interest of the donor to allocate her entire aid budget $A$ to the AoD tranche (i.e. choose $\alpha=0$ ) in order to raise the lower limit for ppe and the

62 Analogously to the previous cases, if $\widetilde{\Theta}$ is set according to (30), the donor sets $\varepsilon^{*}$ for all $\widetilde{\Theta}<\frac{Y+\alpha A}{Y+A}$.

63 This is excluded by the restriction (4) imposed on the government's utility function. Because it is assumed here that the donor knows the functional form (albeit not the parameter $\Theta$ ) of the government's utility function this would not be a credible signal. 
threshold for which this constraint binds government allocation. In other words, there is nothing to be gained for the donor from combining AoD with GBS in terms of counteracting the information asymmetry problem.

The situation differs for $\frac{A}{Y}>1$ : As long as $(1-\alpha) A \leq Y+\alpha A$ (i.e. $\alpha \geq \frac{A-Y}{2 A}$ ) the incentives and results are the same as for $\frac{A}{Y} \leq 1$. Note, however, that in this case, the resulting lower bound $p p e^{*}=(1-\alpha) A$ is smaller than $Y+\alpha A$.

The next step will show why this matters: It can easily be seen that for $\alpha<\frac{A-Y}{2 A}$ the government has no incentive to understate its commitment. For true $\Theta \geq \frac{(1-\alpha) A}{Y+A}$ the government can signal $\widetilde{\Theta}=\Theta$ and allocate in $\Theta(Y+A)$. For lower $\Theta$, however, it has an incentive to overstate its commitment as for any signal $\widetilde{\Theta}<\frac{Y+\alpha A}{Y+A}$ the donor would adjust the matching element to $\varepsilon^{\prime \prime}=1-\widetilde{\Theta}$ and eventually reduce the AoD tranche to $A_{2}^{\prime}=(1-\widetilde{\Theta})(Y+\alpha A) \cdot{ }^{64}$ It is then clearly better for the government to signal $\widetilde{\Theta}=\frac{(1-\alpha) A}{Y+A}$, have the donor set $\varepsilon^{\prime}=\frac{(1-\alpha) A}{Y+\alpha A}$ and generate an upward sloping effective budget constraint as described in the single donor case.

For $\Theta \geq \frac{Y+\alpha A}{Y+A}$ the government will then allocate in $p p e^{*}=\Theta(Y+A)$, and in $p p e^{*}=Y+\alpha A$ otherwise. Evidently, because for $\alpha<\frac{A-Y}{2 A}$, it is always true that $Y+\alpha A<(1-\alpha) A$, this allocation is inferior to the lower limit of $p p e^{*}=(1-\alpha) A$ that result for $\alpha \geq \frac{A-Y}{2 A}$.

Hence, the best the donor can do in a high aid dependency situation where $\frac{A}{Y}>1$, is to balance these two opposing effects and allocate a share $\alpha=\frac{A-Y}{2 A}$ of her aid budget to the fixed GBS tranche and the remaining $1-\alpha=\frac{Y+A}{2 A}$ to her variable AoD tranche. This ensures a lower limit for pro-poor expenditure of $p p e^{*}=Y+\alpha A=(1-\alpha) A=\frac{Y+A}{2}$, which, however, is smaller than the aid budget $A$ and thus inferior to the lower limit for ppe under project aid.

(2) Next, assume the donor imposes a threshold $z$ for the government's signalled commitment below which she reprogrammes her entire aid budget to project aid. As is evident from the previous case, it would not make sense to set this threshold above $\frac{Y+\alpha A}{Y+A}$ as for any $\widetilde{\Theta}$ not smaller than this value, the donor can expect the signal to be a true statement of the government's commitment and the allocation under co-ordinated budget support is the same as under project aid. In the same line of argument, it would not make sense to set the threshold lower than $\frac{\alpha A}{Y+\alpha A}$, as this would allow the government to allocate in ppe $^{*}=\Theta(Y+A)<A$ for a range of $\Theta<\frac{A}{Y+A}$.

For $\frac{A}{Y}<1$ and with a threshold $\frac{\alpha A}{Y+\alpha A}<z<\frac{Y+\alpha A}{Y+A}$, following the same logic as above, the government would then state its true commitment for $\Theta \geq \frac{Y+\alpha A}{Y+A}$ and would want to understate it according to (30) for $\Theta<\frac{Y+\alpha A}{Y+A}$, in either case allocating in ppe $=\Theta(Y+A)$. However, understating $\Theta$ in this way in order to allocate in ppe $=\Theta(Y+A)$ is only possible for $\Theta \geq \frac{z(Y+\alpha A)+(1-\alpha) A)}{Y+A}$, as for any lower $\Theta$ the signal set in line with (30) would become some $\widetilde{\Theta}<z$ and the donor would switch to project aid.

64 Again, understating in line with (30) is not possible as this would imply $\widetilde{\Theta}<0$. 
For $\Theta<\frac{z(Y+\alpha A)+(1-\alpha) A)}{Y+A}$ the government then has two choices: it can either state $\widetilde{\Theta}=z$ and choose a tangent solution on the flat segment of the effective budget constraint, not using up the entire AoD tranche $(1-\alpha) A$; or it can signal some $\widetilde{\Theta}<z$ to induce the donor to switch to project aid and allocate in ppe $=\Theta(Y+A)$ for $\Theta \geq \frac{A}{Y+A}$ and in the corner solution $p p e=A ; x_{0}=Y$ for $\Theta<\frac{A}{Y+A}$.

For a range of $\Theta<\frac{z(Y+\alpha A)+(1-\alpha) A}{Y+A}$ the government will in fact better off with project aid than with the offered GBS/AoD mix and will thus signal $\widetilde{\Theta}<z$. However, for any $\alpha>0$ there will be a lower cut-off point $\underline{\Theta}<z$, below which the government is in turn better off with signalling $\widetilde{\Theta}=z$ and choosing an allocation on the flat segment of the effective budget constraint in $p p e^{*}=\Theta\left[Y+\left(\alpha+\frac{1-\alpha}{z}\right) A\right]$, foregoing a portion of the donor's AoD tranche. ${ }^{65}$

Figure 18 shows the case for $\Theta=\underline{\Theta}$, in which the government is thus just indifferent between signalling $\widetilde{\Theta}<z$ and have the donor switch to project aid (dotted line) and overstating its commitment as $\widetilde{\Theta}=z$ or allocating on the flat segment of the budget constraint (solid line), inducing the donor to disburse only part of her AoD tranche.

Figure 18: Indifference between project aid and partial disbursement of AoD

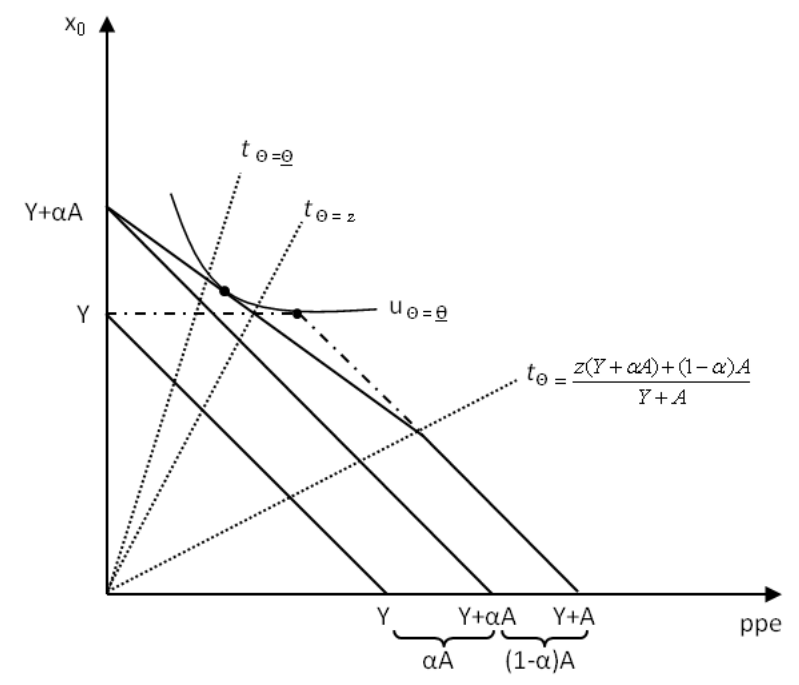

Source: Author's illustration

The implication of this is that for $\frac{(1-\alpha) A}{Y+\alpha A}<1$ and $\Theta>\underline{\Theta}$, the donor can - by coordinating her GBS and AoD tranche - indeed extend the disciplining effect of AoD to her entire aid budget, ensuring self-selection of less committed governments with $\underline{\Theta}<\Theta<\frac{z(Y+\alpha A)+(1-\alpha) A}{Y+A}$ into project aid. The resulting lower bound of $p p e=A$ is clearly better from the donor's perspective than in the case of unco-ordinated budget support (see Table 3).

${ }^{65} \underline{\Theta}$ is given by the smallest positive solution to $\left[\Theta\left[Y+\left(\alpha+\frac{1-\alpha}{z}\right) A\right]\right]^{\Theta}[(1-\Theta)(Y+\alpha A)]^{1-\Theta}=A^{\Theta} Y^{1-\Theta}$. It represents the value for $\Theta$ for which there exists a government utility curve through $p p e=A ; x_{0}=Y$ which is also tangent to the flat segment of the budget constraint to the left of this point (see Figure 18). 
As can be derived from Figure 18, by decreasing $\alpha$ the donor can widen the range for which the government will choose project aid and move $t_{\underline{\Theta}}$ to the left. In a similar fashion, increasing the threshold $z$ also broadens this range, albeit at the cost of having the government choose project aid for higher values of $\Theta$. This means that as long as the donor trusts that the government's commitment is at least moderate (and in particular not smaller than $\underline{\Theta}$ ) she can provide some portion of her aid budget in the form of GBS and only needs to give a share of her budget in the form of an AoD contract, while still making sure that the government will self-select into project aid in case it's commitment to poverty reduction is below the threshold $z$ set by the donor. This way, the donor can ensure that the expenditure on poverty-related items ppe will not be smaller than the aid budget $A$. The higher the donor's trust in the government's commitment, the larger she can choose the share of the GBS tranche $\alpha$.

For $\Theta<\underline{\Theta}$ this approach ensures that only part of the aid budget, namely $(1-\Theta) \alpha A-\Theta Y$, is used to fund $x_{0}$ instead of ppe.

Let us now turn again to the case where $\frac{A}{Y} \geq 1$. As before, as long as $(1-\alpha) A \leq Y+\alpha A$, the same incentives and results as just described apply. For $(1-\alpha) A>Y+\alpha A$ (or $\left.\alpha<\frac{A-Y}{2 A}\right)$, which implies the donor setting $\varepsilon^{\prime}=\frac{(1-\alpha) A}{Y+\alpha A}$ and generating an upwards sloping budget constraint, however, there is an obvious candidate for the donor's threshold $z$ at $\widetilde{\Theta}=\frac{Y}{Y+A}$, as for any $\Theta$ below that threshold, the donor would expect ppe $<A$. However, any such threshold in this case is essentially meaningless, because the government can simply state any $\widetilde{\Theta} \geq z$ and still allocate in $\Theta(Y+A)$ for any $\Theta \geq \frac{Y+\alpha A}{Y+A}$, and in ppe $=Y+\alpha A ; x_{0}=(1-\alpha) A$, accessing the entire aid budget $A$.

The donor is thus clearly better off limiting the share of the AoD tranche in her modality mix to some $(1-\alpha) A<\frac{Y+A}{2}$, accepting that with a large $\alpha$, the lower bound $\underline{\Theta}$ below which the government will not self-select into project aid increases as well.

(3) Alternatively, assume the donor imposes a threshold $z$ (with the same limits as before) below which converts only the fixed GBS tranche $\alpha A$ into project aid but still disburses the remaining $(1-\alpha) A$ as an AoD performance-tranche. Assuming that for signals below the threshold $z$ the donor would then be willing to reward government with a matching grant only for allocations to ppe in excess of $\alpha A$ (i.e. not rewarding the government for her own project expenditure on ppe), the budget constraint would take the shape depicted in Figure 19.

As can easily be seen from Figure 19, the outcome in this setting is essentially the same as when the entire aid budget is reprogrammed for signals below the threshold $z$ : Again, the government for $\Theta \geq \frac{Y+\alpha A}{Y+A}$ states its true commitment $\Theta$ and for $\Theta<\frac{Y+\alpha A}{Y+A}$ can understate its commitment in line with (30) and reach ppe $=\Theta(Y+A)$, as long as $\Theta \geq \frac{z(Y+\alpha A)+(1-\alpha) A}{Y+A}$ for which $\widetilde{\Theta} \geq z$. 
Figure 19: Threshold for fixed tranche

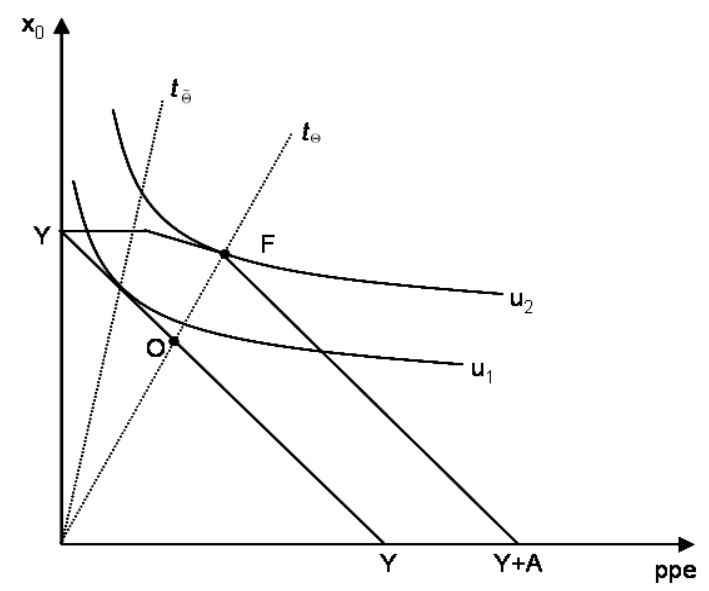

Source: Author's illustration

For $\Theta<\frac{z(Y+\alpha A)+(1-\alpha) A}{Y+A}$, by signalling an infinitesimal $\widetilde{\Theta}$, the government can allocate to ppe $\rightarrow A$. However, there will be some lower threshold for $\Theta$ of $\underline{\Theta}$, below which the government is better off with signalling $\widetilde{\Theta}=z$ and choose a tangent solution, accessing only a portion of the AoD tranche $(1-\alpha) A$.

For $\frac{A}{Y}>1$, the incentives are also the same as in the previous case, where the entire aid budget can be converted to project aid.

Table 5 summarizes the results of this last step of the analysis of a co-ordinated mix of GBS and AoD. As Table 5 shows, by combining the two aid modalities and formulating a threshold for signalled government commitment below which she reprogrammes part of or her entire aid budget, the donor can partly control for the fungibility problem arising under asymmetric information. As long as she can trust that the recipient government's commitment to poverty reduction is not below a certain lower bound, she can ensure that the resulting allocation to pro-poor expenditure will not be lower than in the case of project aid, even if she provides a substantial share of her aid in the form of unconditional GBS. 
Table 5: Donor coordination and aid effectiveness

\begin{tabular}{|c|c|c|c|c|}
\hline Threshold & $\frac{A}{Y} / \alpha$ & $\Theta$ & $\widetilde{\Theta}$ & $p p e^{*}$ \\
\hline $\begin{array}{l}\text { no } \\
\text { threshold }\end{array}$ & $\frac{A}{Y} \leq 1$ & $\begin{aligned} \Theta & \geq \frac{Y+\alpha A}{Y+A} \\
\frac{(1-\alpha) A}{Y+A} & <\Theta<\frac{Y+\alpha A}{Y+A} \\
\Theta & \leq \frac{(1-\alpha) A}{Y+A}\end{aligned}$ & $\begin{array}{c}\Theta \\
1-(1-\Theta) \frac{Y+A}{Y+\alpha A} \\
\widetilde{\Theta} \rightarrow 0\end{array}$ & $\begin{array}{c}\Theta(Y+A) \\
\Theta(Y+A) \\
\lim _{\widetilde{\Theta} \rightarrow 0} p p e=(1-\alpha) A\end{array}$ \\
\hline & $\begin{array}{c}\frac{A}{Y}>1 \\
\alpha=\frac{A-Y}{2 A}\end{array}$ & $\begin{array}{l}\Theta \geq \frac{Y+\alpha A}{Y+A} \\
\Theta<\frac{Y+\alpha A}{Y+A}\end{array}$ & $\begin{array}{c}\Theta \\
\frac{Y+\alpha A}{Y+A}\end{array}$ & $\begin{array}{c}\Theta(Y+A) \\
(1-\alpha) A=\frac{Y+A}{2}\end{array}$ \\
\hline $\begin{array}{l}\text { threshold } \\
\text { both } \\
\text { tranches }\end{array}$ & $\alpha>\frac{A-Y}{2 A}$ & $\begin{array}{c}\Theta \geq \frac{Y+\alpha A}{Y+A} \\
\frac{z(Y+\alpha A)+(1-\alpha) A}{Y+A} \leq \Theta<\frac{Y+\alpha A}{Y+A} \\
\underline{\Theta} \leq \Theta<\frac{z(Y+\alpha A)+(1-\alpha) A}{Y+A} \\
\Theta<\underline{\Theta}\end{array}$ & $\begin{array}{c}\Theta \\
1-(1-\Theta) \frac{Y+A}{Y+\alpha A} \\
\Theta \\
z\end{array}$ & $\begin{array}{c}\Theta(Y+A) \\
\Theta(Y+A) \\
A \\
\Theta\left[Y+\left(\alpha+\frac{1-\alpha}{z}\right) A\right]\end{array}$ \\
\hline $\begin{array}{l}\text { threshold } \\
\text { fixed } \\
\text { tranche }\end{array}$ & $\alpha>\frac{A-Y}{2 A}$ & $\begin{array}{c}\Theta \geq \frac{Y+\alpha A}{Y+A} \\
\frac{z(Y+\alpha A)+(1-\alpha) A}{Y+A} \leq \Theta<\frac{Y+\alpha A}{Y+A} \\
\underline{\Theta} \leq \Theta<\frac{z(Y+\alpha A)+(1-\alpha) A}{Y+A} \\
\Theta<\underline{\Theta}\end{array}$ & $\begin{array}{c}\Theta \\
1-(1-\Theta) \frac{Y+A}{Y+\alpha A} \\
\widetilde{\Theta} \rightarrow 0 \\
z\end{array}$ & $\begin{array}{c}\Theta(Y+A) \\
\Theta(Y+A) \\
\lim _{\widetilde{\Theta} \rightarrow 0} p p e=A \\
\Theta\left[Y+\left(\alpha+\frac{1-\alpha}{z}\right) A\right]\end{array}$ \\
\hline
\end{tabular}

\section{Conclusions}

It is a common perception among many policy makers, but also aid practitioners, that there exist fundamental differences between aid instruments and modalities with respect to the fiduciary risks that arise due to fungibility of the provided aid resources. This perception has had a strong influence on the debate on more effective aid modalities over the past years and has given ground to a widespread scepticism towards budget support as a modality to provide effective aid.

This paper presented a basic principal-agent framework of the aid relationship in face of different aid modalities, namely project aid, unconditional (or ex-ante conditional) general budget support (GBS), and performance-based budget support or 'aid on delivery' (AoD).

We find that even with a fully informed donor, GBS and project aid are essentially equivalent in terms of fungibility of the provided resources over a wide range of combinations of aid dependency and government commitment to poverty reduction, whereas for low and moderate degrees of aid dependency, AoD is clearly more effective in inducing pro-poor expenditure than both these aid modalities.

However, this advantage of AoD over GBS and project aid is eroded over a wide range of values for government commitment, once asymmetric information on the recipient 
government's commitment to reduce poverty is introduced in the model: If the government's commitment is private information (and is not too low), then by misstating its level of commitment to the donor, the recipient government can attain its most preferred allocation, independent of the donor's modality choice. Yet, the incentives are such that the government overstates its commitment to reduce poverty if offered GBS, while in the case of AoD it has an incentive to understate it.

The paper proceeds to examine whether donors can exploit these counteracting incentives by mixing the two aid modalities, thereby eliminating part of the fungibility problem.

The analysis finds that as long as donors do not coordinate their provision of GBS and AoD, a modality mix of this kind only has a very limited effect on the fiduciary risks arising due to the fungibility of the provided resources.

By coordinating their modality mix, however, and establishing a threshold for signalled government commitment, below which they convert either their entire aid budget or only the GBS tranche to project aid, donors can induce the recipient government to self-select into project aid in case its commitment is below this threshold. For government commitment below a lower bound, which is determined by (i) the size of the aid budget, (ii) the share of the aid budget allocated to each modality, and (iii) the (signalled) commitment threshold established by the donor, this approach induces the government to overstate its commitment to poverty reduction, but also to access only part of offered AoD tranche.

In sum, this implies that as long as donors can select recipients, whose commitment they trust not to be below such a specific lower bound, the fiduciary risks of a co-ordinated mix of fixed GBS and variable AoD budget support tranches are not higher than those associated with project aid in the same amount. In practice, it would seem reasonable to expect donors to have at least some idea (or revelation mechanisms) to allow for this kind of selectivity, given that 'donors do not start from a blank canvas [and] in the case of budget support, [...] may have enough information to classify potential recipients' (Morrissey 2006: 339).

The presented model thus provides a strong argument for budget support against project aid. The analysis shows that even in the absence of transaction costs, a mixed approach to budget support is equivalent to project aid over a wide range of aid dependency ratios and government commitment. If one assumes that in practice project-based aid causes substantially higher transaction costs than budget support, and AoD causes higher monitoring and transaction costs than GBS, then there is indeed a strong case for disbursing aid in the form of the co-ordinated modality mix examined here. However, for this approach to be fully effective, donors have to be able (and willing) to closely coordinate their aid provision.

There is a clear policy message in this: Donors should worry less about which aid modality to choose over the other, and much more about taking seriously the coordination and harmonization principles they have committed themselves to in the various high level declarations on aid effectiveness. 
Obviously, this basic model could be extended in various ways.

The most straightforward step would be to more explicitly model transaction costs, although by itself this would not generate any particular new insights into the fundamental mechanics of fungibility demonstrated here.

A second possible extension would be to model repeated aid negotiations between donors and recipient government that could arguably reduce the information asymmetry and may trigger different strategic government behaviour. However, given that a co-ordinated budget support mix in this model turns out not to be subject to fundamentally higher fiduciary risks than project aid even when government commitment is completely private information, one would not expect a reduction of the information asymmetry (which would work in favour of budget support) to alter the main result of the analysis.

Another potentially interesting way to further develop the analysis would be by extending it to more stages of the principal-agent chain, e.g. by introducing a self-interested (i.e. budget maximizing) aid agency or more interest groups on both sides of the aid relation.

It would also be worthwhile to examine more closely some modifications to the offered AoD contract, in particular the possibility to provide a matching grant only for domestic allocations in excess of a certain baseline level.

Finally, it would be interesting to extend the government's policy choices by introducing a multi-dimensional policy space, albeit at the cost of significantly adding to the complexity of the model. 


\section{References}

AfDB / OECD (2005): African Economic Outlook 2004/2005, Tunis / Paris: African Development Bank / Development Centre of the Organisation for Economic Co-operation and Development

Allan, R. S. Schiavo-Campo, T. Garrity (2004): Assessing and Reforming Public Financial Management - A New Approach, World Bank, Washington D.C.

Arndt, C., S. Jones, and F. Tarp (2010): 'Aid, Growth and Development: Have We Come Full Circle?' Journal of Globalization and Development, Volume 1(2), Article 5

BIC (2012): P4R update: World Bank approves Program for Results Policy, Bank Information Center, http://www.bicusa.org/en/Article.12602.aspx (accessed 29.4.2012)

Birdsall, N. and W. Savedoff (2011): Cash on Delivery: A New Approach to Foreign Aid, Center for Global Development, 2nd ed., Washington D.C.

Birdsall, N., A. Mahgoub and W. Savedoff (2010): Cash on Delivery: A New Approach to Foreign Aid, Center for Global Development, CGD Brief November 2010

Burnside, C., D. Dollar (2004): Aid, policies, and growth: revisiting the evidence, World Bank Policy Research Working Paper 3251, Washington, D.C.

Caputo, E. and A. de Kemp (2011): Application of new approach to the evaluation of Budget Support operations: Findings from Mali, Zambia and Tunisia; Synthesis Report from the OECD DAC Network on Development Evaluation, http://www.oecd.org/dataoecd/17/44/49833212.pdf

Caputo, E., A. Lawson and M. van der Linde (2008): Methodology for Evaluations of Budget Support Operations at Country Level - Issue Paper: DRN, ADE, ECO, NC, ECORYS, Assignment for the European Commission; online: http://www.worldbank.org/ieg/nonie/docs/issue_paper.pdf

DFID (2009): Managing Fiduciary Risk When Providing Financial Aid, Department for International Development, How To Note December 2009; http://www.dfid.gov.uk/Documents/publications1/how-to-fiduciary-fin-aid-dec09.pdf

Mekasha, T and F. Tarp (2011): Aid and Growth, What Meta-Analysis Reveals, UNU-WIDER Working Paper No. 2011/22

de Kemp, A., J. Faust and S. Leiderer (2011): Between High Expectations and Reality: An Evaluation of Budget Support in Zambia (2005-2010), Synthesis Report 356, Bonn / The Hague / Stockholm, BMZ / Ministry of Foreign Affairs / Sida

Clemens, M., S. Radelet, R. Bhavnani (2004): Counting Chickens when they Hatch: the Short-Term Effect of Aid on Growth. Center for Global Development, Working Paper 44. Washington, D. C.

Club du Sahel (2000): Aid Reform, A Review of Aid: Co-ordination Mechanisms, SAH / $\operatorname{REFA}(2000) 3$, Paris

Collier, P. et al. (1997): Redesigning Conditionality, in: World Development 25 (9), 1399-1407 
Cordella, T. / G. Dell'Ariccia (2007): Budget Support versus Project Aid. A Theoretical Appraisal, in: The Economic Journal 117 (October), 1260-1279

Devarajan, S. / V. Swaroop (1998): The Implication of Foreign Aid Fungibility for Development Assistance, Washington D.C. / World Bank Policy Research Working Paper 2022)

Devarajan, S., A. Rajkumar, V. Swaroop (1999): What Does Aid to Africa Finance?, Policy Research Working Paper 2092, Africa Region, World Bank,Washington, D.C.

Doucouliagos, H., and M. Padalm (2008): Aid Effectiveness on Growth: A Meta Study, European Journal of Political Economy, 24: 1-24

Easterly, W. (2006): The White Man's Burden: Why the West's Efforts to Aid the Rest Have Done So Much Ill and So Little Good, Penguin Press

Faust, J. / S. Leiderer(2008): Zur Effektivität und politischen Ökonomie der Entwicklungszusammenarbeit, in: Politische Vierteljahresschrift 49 (1), 129-152

Feyzioglu, T. / V. Swaroop / M. Zhu (1998): A Panel Data Analysis of the Fungibility of Foreign Aid, in: World Bank Econ Rev 12 (1), 29-58; online: http://wber.oxfordjournals.org/cgi/content/abstract/12/1/29

Foster, M. / D. Zormelo (2002): How, When and Why does Poverty get Budget Priority? Poverty Reduction Strategy and Public Expenditure in Ghana, ODI Working Paper 164

Fozzard, A. (2001): The Basic Budgeting Problem. Approaches to Resource Allocation in the Public Sector and their Implications for Pro-Poor Budgeting, London: Overseas Development Institute, (ODI Working Paper 147)

Gunning, J.W. (2006): Budget Support, Conditionality, and Impact Evaluation, in: S. Koeberle / Z. Stavreski / J. Walliser (eds.), Budget Support as More Effective Aid? Recent Experiences and Emerging Lessons, Washington D.C.: World Bank, 295-310

Gibson, C. / K. Andersson / E. Ostrom / S. Shivakumar (2006): The Samaritan's Dilemma: The Political Economy of Development Aid. Oxford, Oxford University Press.

Gomanee, K., O. Morrissey, P. Mosley, A. Verschoor (2005): Aid, Government Expenditure, and Aggregate Welfare, World Development 33(3), 355-370

Grossman, G. M. / E. Helpman (2001): Special Interest Politics, MIT Press, Chapter 7

Grüner, H. P. (2008): Wirtschaftspolitik: Allokationstheoretische Grundlagen und politischökonomische Analyse, Berlin/Heidelberg, Springer

Hauck, V. / O. Hasse / M. Koppensteiner (2005): EC Budget Support. thumbs up or down?, Maastricht: European Centre for Development Policy Management (Discussion Paper 63)

Hefeker, C. (2005): Project Aid or Budget Aid? The Interests of Governments and Financial Institutions, HWWA Discussion Paper 309

Hefeker, C. / K. Michaelowa (2003): Can Process Conditionality Enhance Aid Effectiveness? The Role of Bureaucratic Interest and Public Pressure, HWWA Discussion Paper 239

HLF (2003): Rome Declaration on Harmonization, online: http://www.oecd.org/dataoecd/54/50/31451637.pdf (accessed 4.5.2012) 
HLF (2005): Paris Declaration on Aid Effectiveness, Paris; online: http://www.oecd.org/dataoecd/30/63/43911948.pdf

HLF (2008): Accra Agenda for Action; online: http://www.oecd.org/dataoecd/58/16/41202012.pdf (accessed 4.5.2012)

HLF (2011): Busan Partnership for Effective Development Cooperation, online: http://www.oecd.org/dataoecd/54/15/49650173.pdf (accessed 4.5.2012)

Hoverm, I.-G. (2009): Budget Support: Why and how we are delivering, European Centre for Development Policy Management (ECDPM), Maastricht, Discussion Paper 88A

IBP (2010): Open Budgets Transform Lives: The Open Budget Survey 2010, International Budget Partnership, Washington D.C.

IDD and Associates (2006): Evaluation of General Budget Support: Synthesis Report: University of Birmingham

Ivanova, A. (2006):Outcomes-based Conditionality: Its Role and Optimal Design, IMF Working Paper WP/06/128

Jack, W. (2008): Conditioning Aid on Social Expenditures, in: Economics \& Politics 20 (1), 125-140; online: http://www.blackwell-synergy.com/doi/abs/10.1111/j.14680343.2007.00325.x

Klingebiel, S. (2012): Results-based Aid (RBA) and its Application to Promote Good Governance, mimeo

Klingebiel, S. / S. Leiderer /P. Schmidt (2005): Programme Financing and Public Budgets: New Instruments and Starting Points of Development Policy, Bonn, Deutsches Institut für Entwicklungspolitik / German Development Institute, (Discussion Paper 3/2005)

Klingebiel, S. / S. Leiderer / P. Schmidt (2007): Wie wirksam sind neue Modalitäten der Entwicklungszusammenarbeit? Erste Erfahrungen mit Programme-Based Approaches (PBAs), Bonn, Deutsches Institut für Entwicklungspolitik / German Development Institute, (Discussion Paper 7/2007)

Koeberle, S. (2003): Should Policy-Based Lending Still Involve Conditionality?, in: The World Bank Research Observer 18 (2), 249-273

Koeberle, S. et al. (eds.) (2005): Conditionality Revisited : Concepts, Experiences, and Lessons, Washington, DC: World Bank

Koeberle, S. / Z. Stavreski (2006): Budget Support: Concept and Issues, in: S. Koeberle / Z. Stavreski / J. Walliser (eds.), Budget Support as More Effective Aid? Recent Experiences and Emerging Lessons, Washington D.C.: World Bank, 3-26

Koeberle, S. / J. Walliser / Z. Stavreski (eds.) (2006): Budget Support as More Effective Aid? Recent Experiences and Emerging Lessons, Washington, DC: World Bank

Kolstad, I. (2005): Direct Budget Support and Corruption, U4 Anti-Corruption Resource Centre, Chr. Michelsen Institute, Bergen, U4 Issue 1:2005 
Lahiri, S. / P. Raimondos-Møller (2004): Donor Strategy under the Fungibility of Foreign Ai, Economics \& Politics, 16(2)

Leandro, J. E. / H. Schafer / G. Frontini (1999): Towards a More Effective Conditionality: An Operational Framework, in: World Development 27 (2), 285-299

Leiderer (2004): Öffentliches Budgetmanagement in Entwicklungsländern - Analyseinstrumente und Ansatzpunkte der programmorientierten Entwicklungszusammenarbeit, Deutsches Institut für Entwicklungspolitik / German Development Institute (Berichte und Gutachten 7/2004)

Leiderer, S. (2010): Budget Support as and Aid Instrument: Neither Pandemonium nor Panacea, Bonn: Deutsches Institut für Entwicklungspolitik / German Development Institutte (Briefing Paper 9/2010)

Leiderer, S. / B. Hodick / E. Kabey / M. Roll / S. Schnitzer / J. Ziegenbein (2007): Public Financial Management for PRSP Implementation in Malawi - Formal and Informal PFM Institutions in a Decentralising System, Bonn: Deutsches Institut für Entwicklungspolitik / German Development Institute (Studies 28)

Lu, C. / M. Schneider / P. Gubbins / K. Leach-Keman / D. Jamison / C. Murray (2010): Public Financing of Health in Developing COuntries: A Cross-Country Systematic Analysis, The Lancet $375,1375-87$

Martens, B. / Mummert, U./ Murrell, P. (2002) (eds.): The Institutional Economics of Foreign Aid. Cambridge, Cambridge University Press.

McGillivray, M. / O. Morrissey (2000): Aid Fungibility in Assessing Aid: Red Herring or True Concern?, in: Journal of International Development 12 (3), 413-428

McGillivray, M. / O. Morrissey (2001a): Fiscal Effects of Aid, UNU-WIDER Discussion Paper No. $2001 / 61$

McGillivray, M. / O. Morrissey (2001b): Aid Illusion and Public Sector Behaviour, Journal of Development Studies, 37:6, 118-136

McKay, A. (2002): Assessing the Impact of Fiscal Policy on Poverty (UNU/WIDER Discussion Paper No. 2002/43)

Morrissey, O. (2002): Making Debt Relief Conditionality Pro-poor, Helsinki (Discussion Paper / UNU-WIDER 2002/04)

Morrissey, O. (2006): Fungibility, Prior Actions, and Eligibility for Budget Support, in: S. Koeberle / Z. Stavreski / J. Walliser (eds.), Budget Support as More Effective Aid? Recent Experiences and Emerging Lessons, Washington D.C.: World Bank, 333-343

Mosley, P., J. Hudson and A. Verschoor(2004): Aid, Poverty Reduction and the 'New Conditionality', in: The Economic Journal 114, F217-F243

OECD-DAC (2003): Harmonizing Donor Practices for Effective Aid Delivery, Development Assistance Committee of the Organization for Economic Co-operation and Development, Paris OECD-DAC (2006): Harmonising Donor Practices for Effective Aid Delivery, Volume 2: Budget Support, Sector Wide Approaches and Capacity Development in Public Financial Management, DAC Guidelines and Reference Series, Paris 
OECD-DAC (2008): 2008 Survey on Monitoring the Paris Declaration: Making Aid more Effective by 2010, OECD, Paris

Pack, H. / J. Rothenberg Pack (1993): Foreign Aid and the Question of Fungibility, in: The Review of Economics and Statistics 75 (2), 258-265

Persson, T. / G. Tabellini (1999): Political Economics and Public Finance (NBER Working Paper 7097)

Pettersson, J. (2007): Foreign sectoral aid fungibility, growth and poverty reduction, in: Journal of International Development 19 (8), 1074-1098

Rakner, L., L. Mukubvu, N. Ngwira, K. Smiddy, A.Schneider (2004): The Budget as Theatrethe Formal and Informal Institutional Makings of the Budget Process in Malawi, Final Report, Chr. Michelsen Institute, Bergen, mimeo

Resnick, D. (2012): Two Steps Forward, One Step Back: The Limits of Foreign Aid on Malawi's Democratic Consolidation, UNU-WIDER Working Paper 2012/28, Helsinki

Roberts, J. (2003): Managing Public Expenditure for Development Results and Poverty Reduction, ODI Working Paper (203)

Roodman, David, 2007: The Anarchy of Numbers: Aid, Development and Cross-country Empirics, World Bank Economic Review 21 (2), 255-277.

Rothmann, I. / A. ten Have (2004): Tracking Financial Flows to Education for All (EFA), Draft Synthesis Report, Rotterdam: ECORYS; online: http : //www.mickfoster.com/docs/TrackingFinancialFlowstoEF ADraftNov04.pdf

Schmidt, P. (2006) Budget support in the EC's development cooperation, Bonn, Deutsches Institut für Entwicklungspolitik / German Development Institute (Studies 20)

Sobhee, S. and S. Nath (2009): Is Donors' Concern About the Fungibility of Foreign Aid Justified?: A Panel Data Analysis, The Journal of Development Areas, 43:2, 299-311

Verschoor, A. (2002): Aid and the Poverty-Sensitivity of the Public Sector Budget, Research PRogramme on Risk, Labour Markets and Pro-poor Growth: Occasional Paper 3, Department of Economics, University of Sheffield

Wagstaff, A. (2011): Fungibility and the Impact of Development Assistance: Evidence from Vietnam's Health Sector, Journal of Development Economics 94(1), 62-73

White, H. and G. Dijkstra (2003): Programme Aid and Development: Beyond Conditionality, Routledge, London

World Bank (1998): Assessing Aid. What Works, What Doesn’t and Why, New York: Oxford University Press

World Bank (2007): World Development Indicators 2007, Washington D.C.

World Bank (2012): Operational Policy 9.0: Programme-for-Results Financing, $\quad$ http://web.worldbank.org/WBSITE/EXTERNAL/PROJECTS/EXTPOLICIES/ EXTOPMANUAL/0,,contentMDK:23101116 pagePK:64141683 piPK:64141620 theSitePK:502184,00.html (accessed 18.4.2012) 
Zampelli, E. M. (1986): Resource fungibility, the flypaper effect, and the expenditure impact of grants-in-aid, in: The Review of Economics and Statistics 68 (1), 33-40 